For Publication in Thin-Walled Structures

\title{
Numerical investigation and development of design formula for cylindrically curved plates on ships and offshore structures
}

\author{
Joo Shin Park ${ }^{1}$, Jeom Kee Paik ${ }^{2,3,4}$ and Jung Kwan Seo ${ }^{3 *}$ \\ ${ }^{1}$ Central Research Institute, Samsung Heavy Industries Co., Ltd., Geoje, Republic of Korea \\ ${ }^{2}$ Department of Naval Architecture and Ocean Engineering, Pusan National University, \\ Busan, Republic of Korea \\ ${ }^{3}$ The Korea Ship and Offshore Research Institute, Pusan National University, Busan, \\ Republic of Korea \\ ${ }^{4}$ Department of Mechanical Engineering, University College London, UK \\ *Corresponding author. Tel.: +82 51 510-2415. Email address: seojk@pusan.ac.kr(JK Seo).
}

\begin{abstract}
Although guidelines exist for evaluation of the buckling strength of curved plates on ships and offshore structures, they do not reflect the effects of curvature or detail their geometric characteristics. From estimations made using cylinder models, it is known that curvature is expected to increase the buckling strength and the ultimate strength of a curved plate. Therefore, it may be designed accordingly. This study aims to clarify and examine the fundamental behaviour of cylindrically curved plates under axial compression and lateral pressure via a series of elasto-plastic large deflection analyses. On the basis of these results, the effects of curvature, initial deflection, slenderness and aspect ratio, boundary conditions and secondary buckling behaviour are discussed and developed with a modified Faulkner's formula to obtain a double beta formula to predict the ultimate strength of the curved plate.
\end{abstract}

Keywords: cylindrically curved plate, stiffened curved plate, ultimate strength, design formula, ships and offshore structures

\section{Introduction}

Cylindrically curved plates are extensively used in ship structures, such as in deck plating, side shell plating, and bilge circle parts of ships, in oil and gas storage, in wind towers, and in the SPAR structures of offshore installations. However, the current guideline that is used to evaluate the buckling strength of a ship's curved plate is insufficient to understand the effect of curvature and geometrical characteristics. From estimations that have been made using cylinder models, it is known that, in general, curvature increases the buckling strength of a curved plate that is subjected to axial compression and curvature is also expected to increase the ultimate strength.

The past several decades have witnessed theoretical and practical research on imperfection sensitivity [1-3], elastic critical moments [4-5] and the ultimate strength of a curved plate or/and panel [6-7]. The focus on curved plate studies has mostly concerned idealised structural models and their application to 
land based structures. However, there has been less investigation of the curved plates of ships and offshore structures compared with land-based structures, due to the implications of the former. Ships and offshores structures have mostly been considered in the design and analysis at the flat stiffened plate level or the flat bare plate level. Therefore, this paper first aims to understand the characteristics of the curved plates of ships and offshore structures that are subjected to axial compression. Applied axial compression mostly governs load according to ship motion and plate curvature (the bilge as shown in Fig. 1). This study considers the effects of curvature, initial deflection, slenderness ratio and aspect ratio.
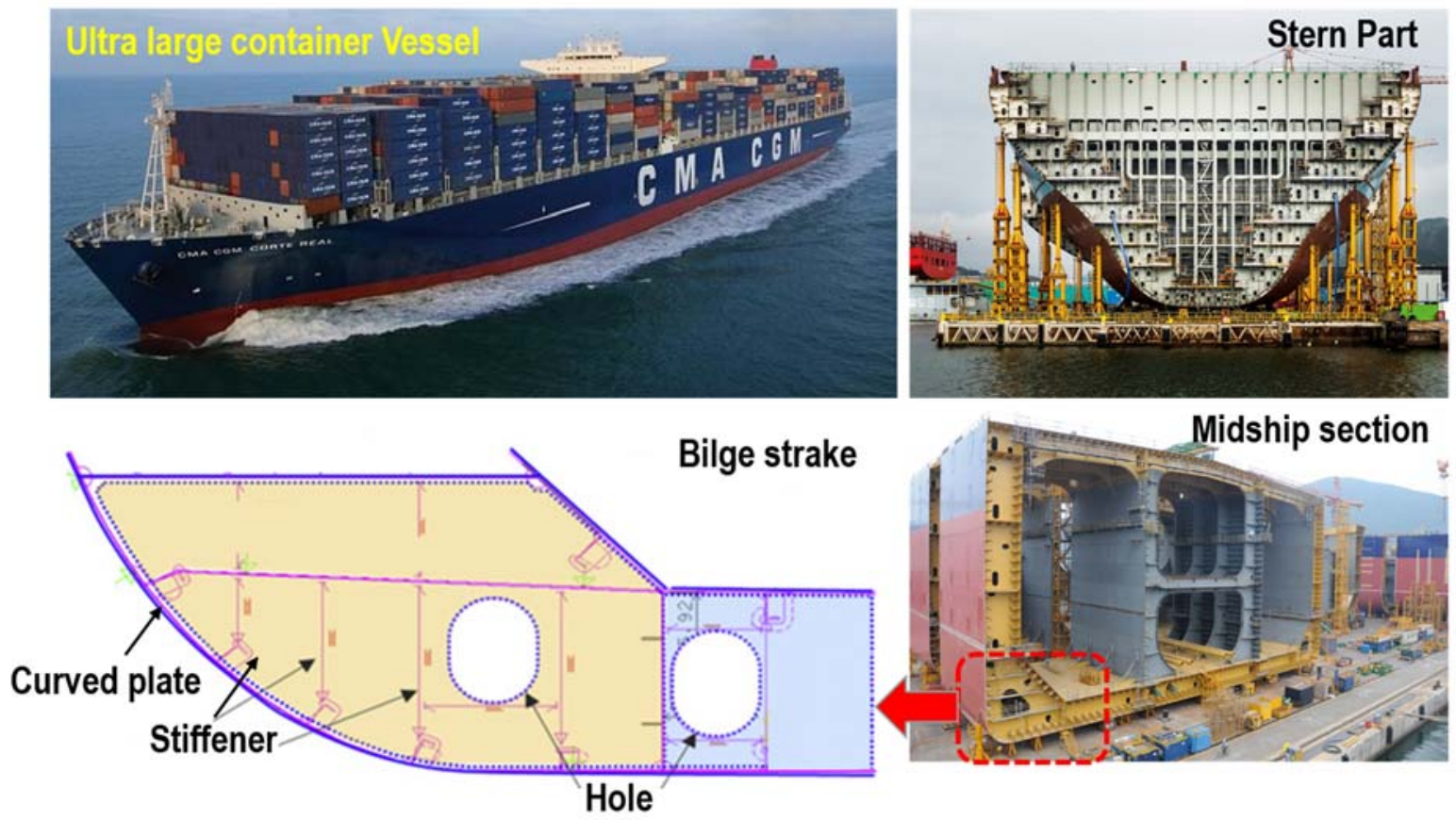

Fig. 1. Cylindrically curved plate panel of ship structures

Recently, structural behaviour of unstiffened and stiffened curved plates have been numerically investigated subjected to various loading conditions and with several geometrical characteristics for ships and offshore structures. We will next review the latest research related to buckling and the ultimate strength of cylindrically curved plates and stiffened plated ships and offshore structures with design formulae.

A series of FE analyses have investigated the elastic and buckling and plastic collapse behaviour of ship bilge strakes of unstiffened curved plates and, based on the results, a simple formula has been derived to calculate buckling and ultimate strength $[8,9]$. Park et al. [10] considered the curved stiffened shell of container bilge stake under combined axial compression and hydrostatic pressure loads. Kwen et al. [11] performed FE analyses for curved plates that studied the aspect ratio, slenderness ratio and curvature. They then developed a simple formula to predict ultimate strength with plasticity correction. Cho et al. [12] performed numerical analyses and tests on six types of stiffened curved plates that are used on ship structures. 
Some details of buckling and post-buckling collapse behaviour have been presented for unstiffened cylindrically curved plates with variations in the curvature, slenderness ratio, aspect ratio, and initial imperfection [13-15]. In addition, a simple formula incorporating the effects of several parameters was proposed for use in predicting the classification society buckling formulae [16, 17]. Kim et al. proposed design formulae with fundamental elastic buckling and post-buckling behaviour though FE analyses of curved plates. However, the geometric parameters that they considered are limited, such as flank's angles and thickness. It should be noted that a more detailed investigation with varying geometric parameters and development of a design formula is required for applicable marine industrial practices. Stiffened panel level investigation and the development of design formula are also limited. Most of the results of previous research similarly predict and develop the buckling and ultimate strength of unstiffened plates [18-21].

Although there are guidelines for evaluating the buckling strength of curved plate level, they do not reflect the effects of curvature or detail the geometric characteristics of a cylindrically curved plate. Studies that have attempted to develop design formulae for unstiffened cylindrically curved plates are limited. However, unstiffened cylindrically curved plates are required for modern design requirements for larger, lighter and faster ships. This knowledge should be developed, at least for marine loading intensities and geometries, although some useful formulations for the ultimate compressive strength of unstiffened plates can be found in the literature [23-27]. Therefore, unstiffened cylindrically curved plates should be investigated with details of structural behaviour.

In the present paper, we aim to clarify and examine the fundamental behaviour of cylindrically curved plates under axial compression. Therefore, a series of elasto-plastic large deflection analyses are performed. On the basis of the calculated results, the effects of curvature, initial deflection, slenderness ratio and aspect ratio, and secondary buckling on the characteristics of ultimate strength behaviour under axial compression are discussed and we derive a closed-form expression to calculate the ultimate strength though double beta forms. Double beta formulae are widely used to predict the ultimate strength of unstiffened plates under axial compression. The details of development of this formula are found in Section 4.

\section{Numerical modelling of the curved plates}

\subsection{Target curved plate of ship structure}

Target curved plated structures form the bottom bilge strakes of a typical container ship's structure. The numerical model considers bilge stiffened plate structures that are surrounded by bottom girders and by a transverse floor, as shown in Fig. 2. The curved plate has dimensions of length $(a)$, breadth (b), plate thickness $(t)$, and flank angle $(\theta)$, where the breadth is related to the flank angle, through $b=\theta$ $\times R(R=$ the radius as indicated in Fig. 1). In this study, the breadth is kept constant at 1,000 mm, based 
on the maximum size of the longitudinal space in existing ships.

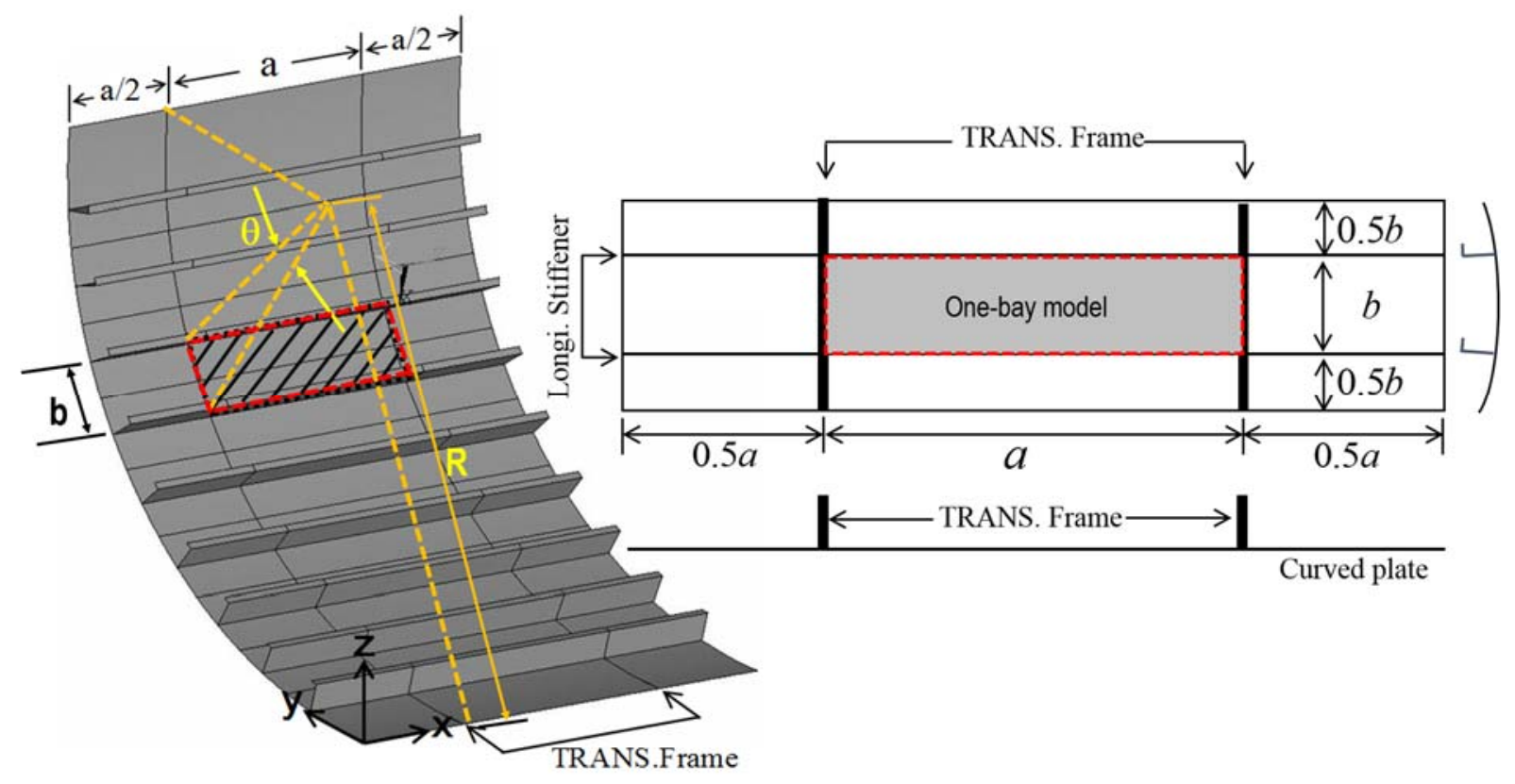

Fig. 2 A cylindrically curved plate subjected to axial loading in ship structures [22]

\subsection{FE modelling}

\subsubsection{Elements and material nonlinearity}

To simulate the actual structural behaviour of curved plates, it is necessary to pay attention to several factors of element and material nonlinearity. Because the thin steel plate elements of curved stiffened panels are subject to local and global buckling, and the plates and stiffeners to in- and out-of-plane buckling effects, the element chosen must be capable of modelling these buckling phenomena and its associated behaviour [11-14]. It must be capable of modelling the structural behaviour in both the linear and non-linear regions, including large displacements, elasto-plastic deformations and associated plasticity effects. A commercial nonlinear FEA code [28] was used in this study for the ultimate strength computations of the curved plates. The shell elements in the ANSYS element library generally satisfy these criteria and can thus be used to model the steel plate elements of the stiffened panels. Although different types of shell elements are available in this library [28], shell 181 three-dimensional (3D) thin isoparametric quadrilateral elements with four nodes and six degrees of freedom per node were used to model the steel plate elements in this study, as they are considered the most suitable for the proposed FEA.

The ANSYS classical metal plasticity model was used in all of the analyses provided here. This model implements the von Mises yield surface to define isotropic yielding, associated plastic flow theory and either perfect plasticity or isotropic hardening behaviour. Here, a simplified bilinear stress-strain curve with no strain hardening (i.e., the yield stress does not change with an increase in plastic strain) was used. Also, material properties are considered, such as yielding stress and the modulus of elasticity, 
being 352.8MPa and 205.8GPa, respectively.

\subsubsection{Mesh conversance study}

In FE analysis, the proper selection of mesh size and layout is critical. Although it is desirable to use as many elements as possible in such an analysis, doing so is computationally expensive in terms of time and resources. The calculations were conducted to determine the level of mesh refinement required by FE modelling to ensure convergence for a curved plate with an aspect ratio 3.1, a plate thickness of $15 \mathrm{~mm}$ and a flank angle of 10 degrees. Fig. 3 shows the relationships of buckling stress and the division number of elements of the curved plate varying the change mesh numbers. According to the mesh conversance results, it can be confirmed that the optimised numbers of the element are 20 divided in the width direction and 62 divided in the longitudinal direction. Thus, the element number must be carefully considered because its sensitively affects the buckling shape and buckling/ultimate stress.

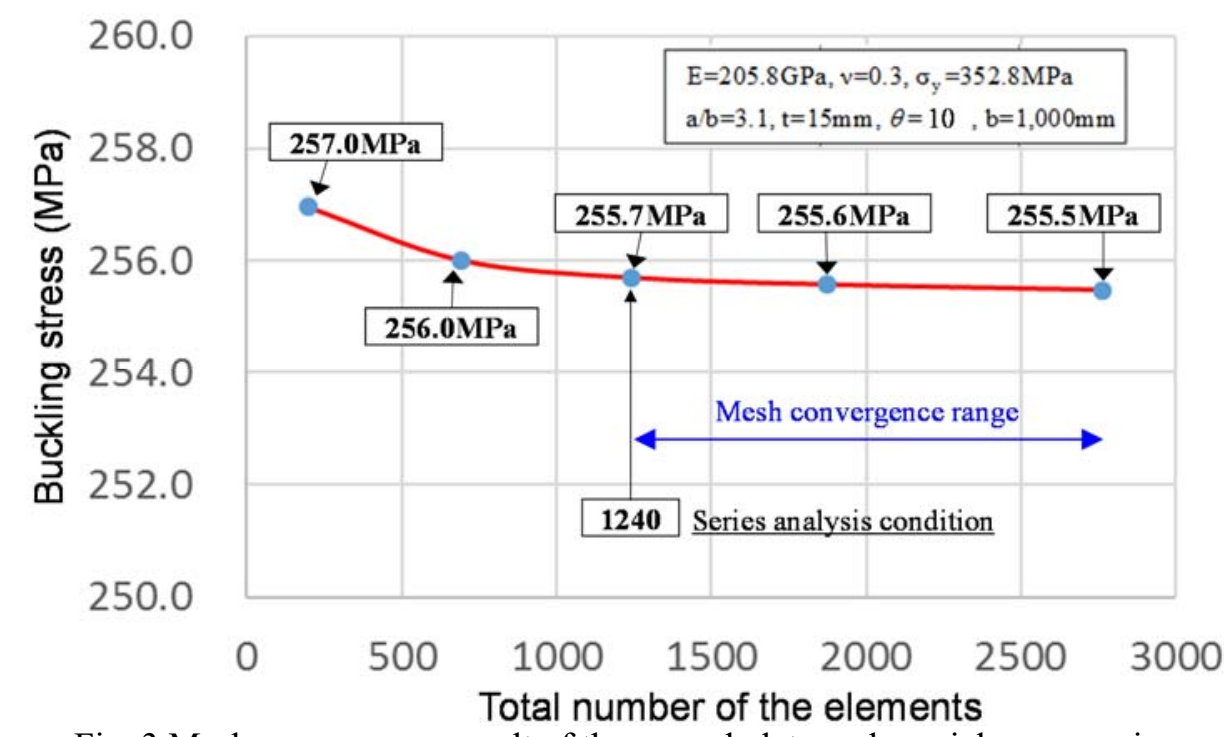

Fig. 3 Mesh convergence result of the curved plate under axial compression

\subsubsection{Boundary conditions}

The boundary of the target curved plate elements is supported by two longitudinal stiffeners and two transverse frames as shown in Figs. 2 and 4. Generally, the degree of rotational restraint at the plate boundary is neither zero nor infinite, the former being equivalent to the simply supported boundary condition and the latter corresponding to the fixed (or clamped) condition, largely because the degree of rotational restraints at the plate boundary depends on the torsional rigidity of its supporting members which is neither zero nor infinite [29].

For the purposes of practical design and for the benefit of mathematical simplicity, the simply supported boundary condition (i.e., with zero rotational restraint) is often adopted in ship and offshore industries when design calculation methods are applied. When this boundary condition is adopted, the so-called one-bay plate model as shown in Fig. 4(a) may be used. There are two types of one-bay models: $1 / 2+1 / 2$ - and 1 (one)-bay models. 
The both $1 / 2+1 / 2$ - and 1-bay models are effective for investigating a buckling pattern in a continuous plate with torsional rigidity of the transverse frame. Extension of the FE model, which is often termed the two $(1 / 2+1+1 / 2)$-bay plate model, can produce a more accurate and refined nonlinear resolution of the issue of rotational restraints. However, the extended model can more accurately account for the relative degree of torsional rigidity of the support members to the bending rigidity of the plate element itself, although some more computational effort is be required. For example, in the case of the $1 / 2+1 / 2$ bay model, the transverse frame should be modelled. Also, buckling and collapse behaviour changes depending on the dimensions of the surrounding supporting members; hence, it is difficult to estimate the buckling strength and mode variation for an isolated curved plate.

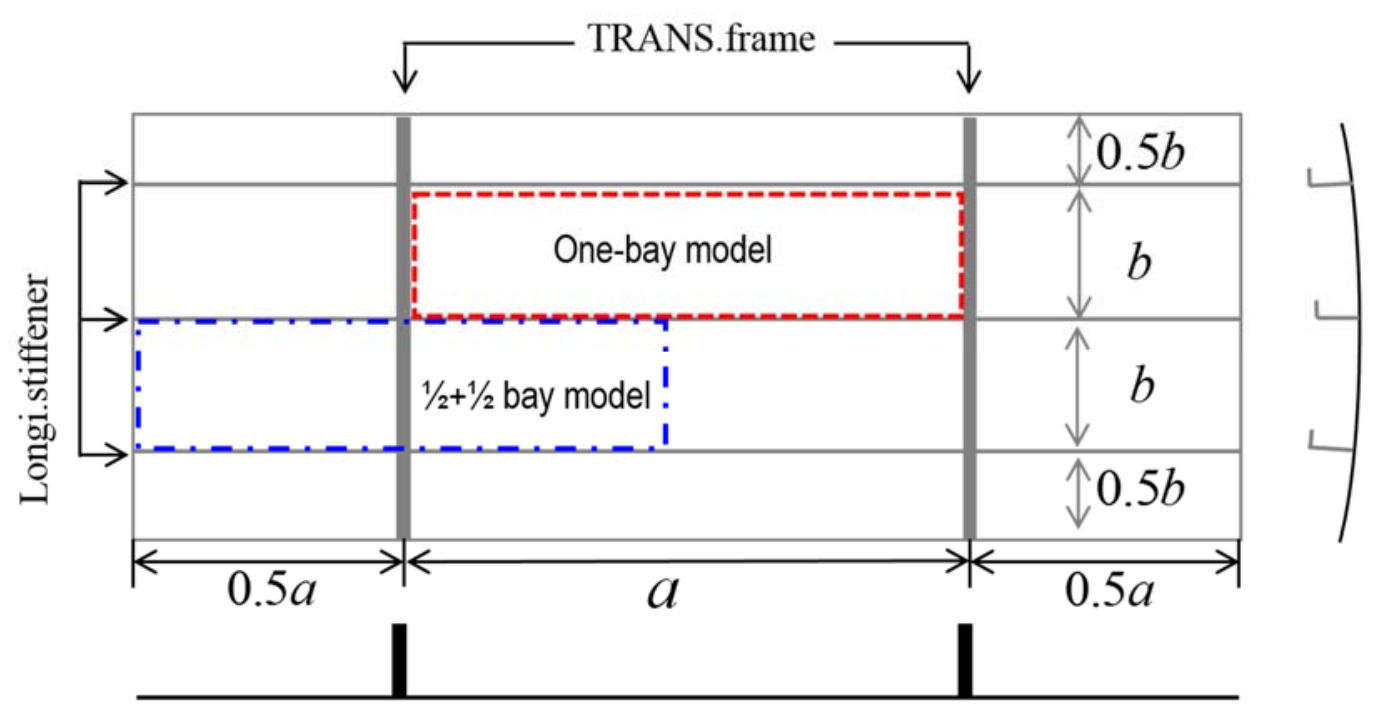

(a) Boundary conditions of the curved plate panel structures

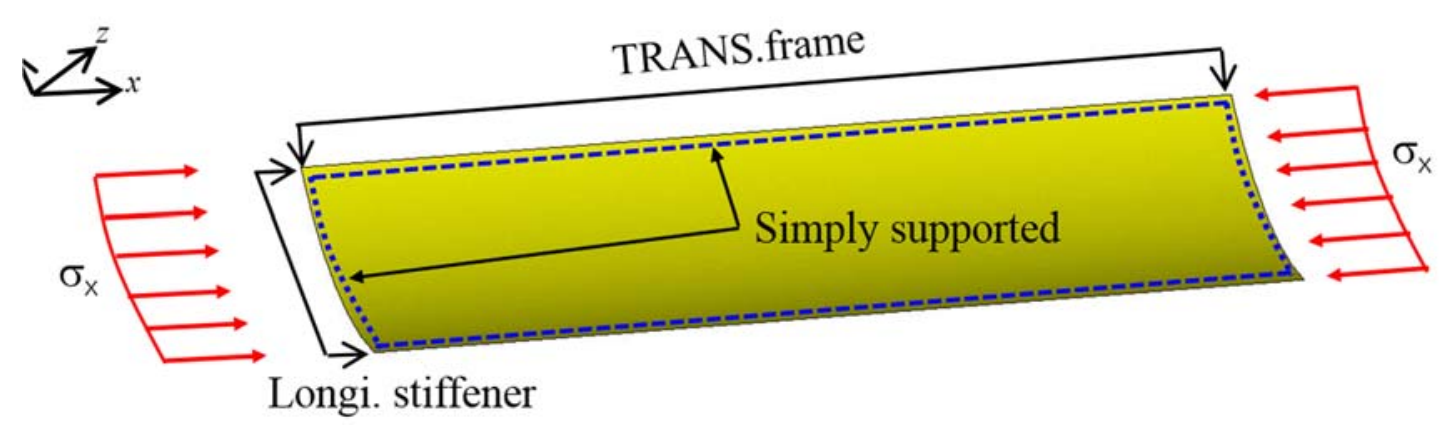

(b) Loading conditions of the target curved plat

Fig. 4 The one-bay cylindrically curved plate model

In terms of structural design, when evaluating the buckling and ultimate strength for a curved plate in this study, the adoption of a simply supported boundary condition gives more conservative results than the clamped condition. Moreover, for the safe design of ships and offshore structures, this design approach, of using the simply supported boundary condition, provides a proper safety factor. As a result, from the aspect of structural design, one bay model and all (four) edges simply supported; that is, with 
zero lateral defection and zero rational restraint, was adopted as shown in Fig.4(b). In addition, the clamped condition is also compared with the effect of ultimate strength of the simply supported boundary condition in Sub-section 3.4.

\subsubsection{Initial deflection}

To fabricate stiffened plates in ship and offshore structures, fillet welding is usually performed to provide stiffeners on the plating. Consequently, welding-induced initial imperfections, such as initial deflection and residual stress, are produced in the plating and stiffeners [23, 26, 27]. In advanced ship structural design, capacity calculations of ship plating should be performed to consider the influence of the initial deflection and residual stress induced by the welding process. However, thus far there is considerably little information regarding the behaviour and pattern of initial imperfection of curved plate panels. Therefore, this study is assumed and applied the initial imperfection from the flat plate structures.

Initial imperfections, such as residual stress and/or initial deflection, exist in the manufacturing and assembly processes by thermo-mechanical processes such as cutting and welding. The initial deflection wave is generally represented as Eq. (1). The equation was derived by idealising flat plate to beam and assuming the simply supported boundary condition [26].

$$
w_{o}=w_{o p l} \sum_{m} \sum_{n} \sin \frac{m \pi x}{a} \sin \frac{n \pi y}{b}
$$

where $m$ and $n$ represent the number of half-waves in $\mathrm{x}$ - and y-directions, respectively.

Fig. 5 shows the initial deflection shape of the eigenvalue model through an elastic buckling analysis under longitudinal compressive load. Although the initial deflection modes are different according to the increasing flank angel of curved plate, the applied initial deflection shapes are used in elastic buckling analysis results [23].

There are two general alternative formulations of the maximum magnitude of the $w_{\text {opl }}$ of plate initial defection, that is, Eqs. (2a) and (2b), have different usage backgrounds. Eq. (2a) gives a more precise representation of the plate characteristics, which is a function of the plate slenderness ratio. However, Eq. (2b) is supported by industrial practice, and states that $w_{\text {opl }}$ is a function only of plate thickness. In current industrial practice, an initial imperfection induced by welding tends to have less amplitude than $\mathrm{Eq}$ (2) due to improved welding distortion control techniques.

$$
\frac{w_{o p l}}{t}=\left\{\begin{array}{lr}
0.025 \beta^{2} \text { for slight level } \\
0.1 \beta^{2} \text { for average level } \\
0.3 \beta^{2} \text { for severe level }
\end{array}\right\}
$$




$$
\frac{w_{o p l}}{t} \leq 0.01
$$

where $t$ is the thickness of the plate and $\beta$ represents the slenderness ratio of plate, which is calculated using

$$
\beta=b / t \sqrt{\left(\sigma_{y} / E\right)}
$$

However, there is limited information on the measurement or actual initial imperfection of a curved plate of ships structures. For influence of initial deflection, Eq. (2a) is applied due to considering the plate characteristics in terms of the plate slenderness ratio and thickness. Also the general observation of curvature, aspect ratio and structural behaviour are considered in Eq. (2b) for simplification in this study. Welding-induced residual stress is also important, but this FE model does not consider its effects. Further studies may use experimental data to consider the influence of the residual stress of curved plates.

According to previous assumptions such as boundary and loading conditions, the material properties and geometric imperfections are correctly modelled, and an appropriate finite element is chosen. The non-linear FEA method is the most refined method among those currently available and is believed to provide the most accurate solutions.

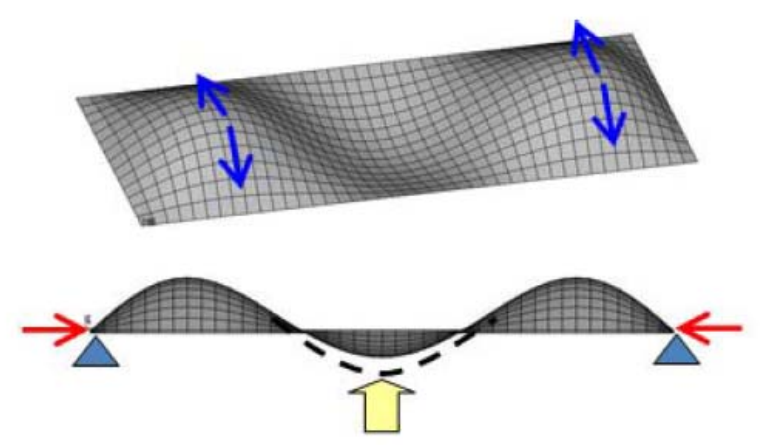

(a)

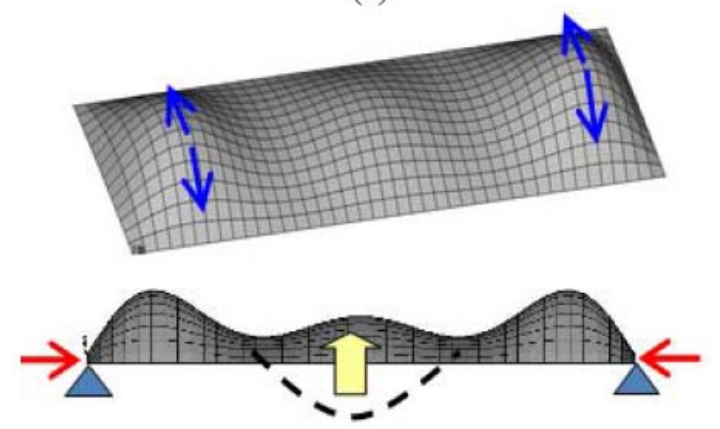

(c)

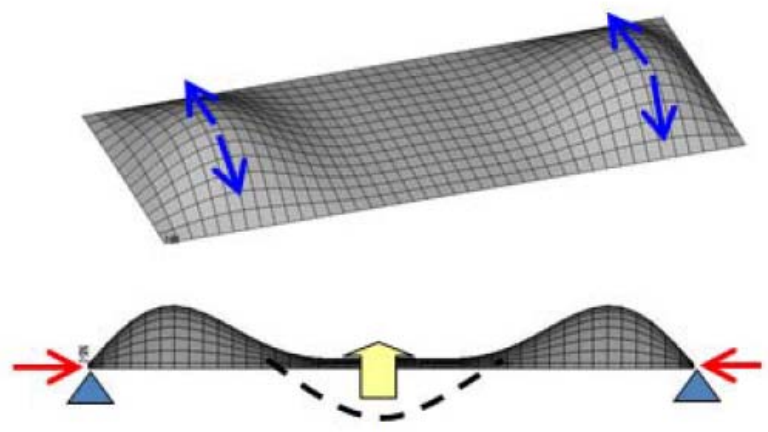

(b)

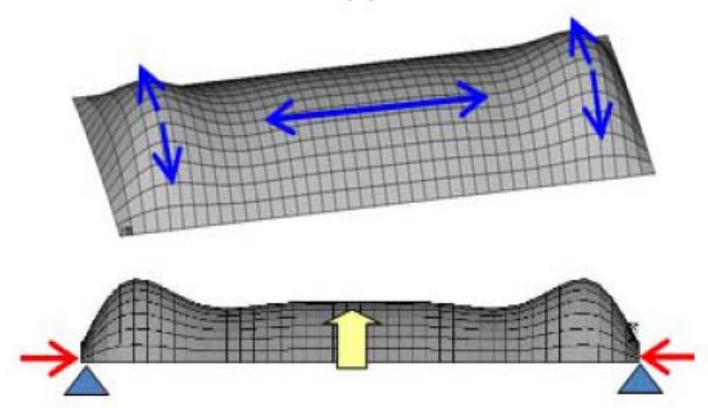

(d)

Fig. 5 Elastic buckling mode with varying flank angles (a) $2^{\circ}$, (b) $3^{\circ}$, (c) $5^{\circ}$, and (d) $10^{\circ}$ under longitudinal compression [16] 


\section{Investigation of the numerical FE results}

\subsection{Influence of curvature}

A series of parametric analyses are performed by varying the curved plate from $0.01 t$ to $0.4 t$ of maximum plate initial deflection $\left(w_{\max }\right)$ and flat to 45 degrees of curvature, respectively. Fig. 6 shows a percentage comparison of the ultimate strength with varying initial deflections and curvatures between the curved and flat plate on 3.0 of aspect ratio with $15 \mathrm{~mm}$ of plate thickness.

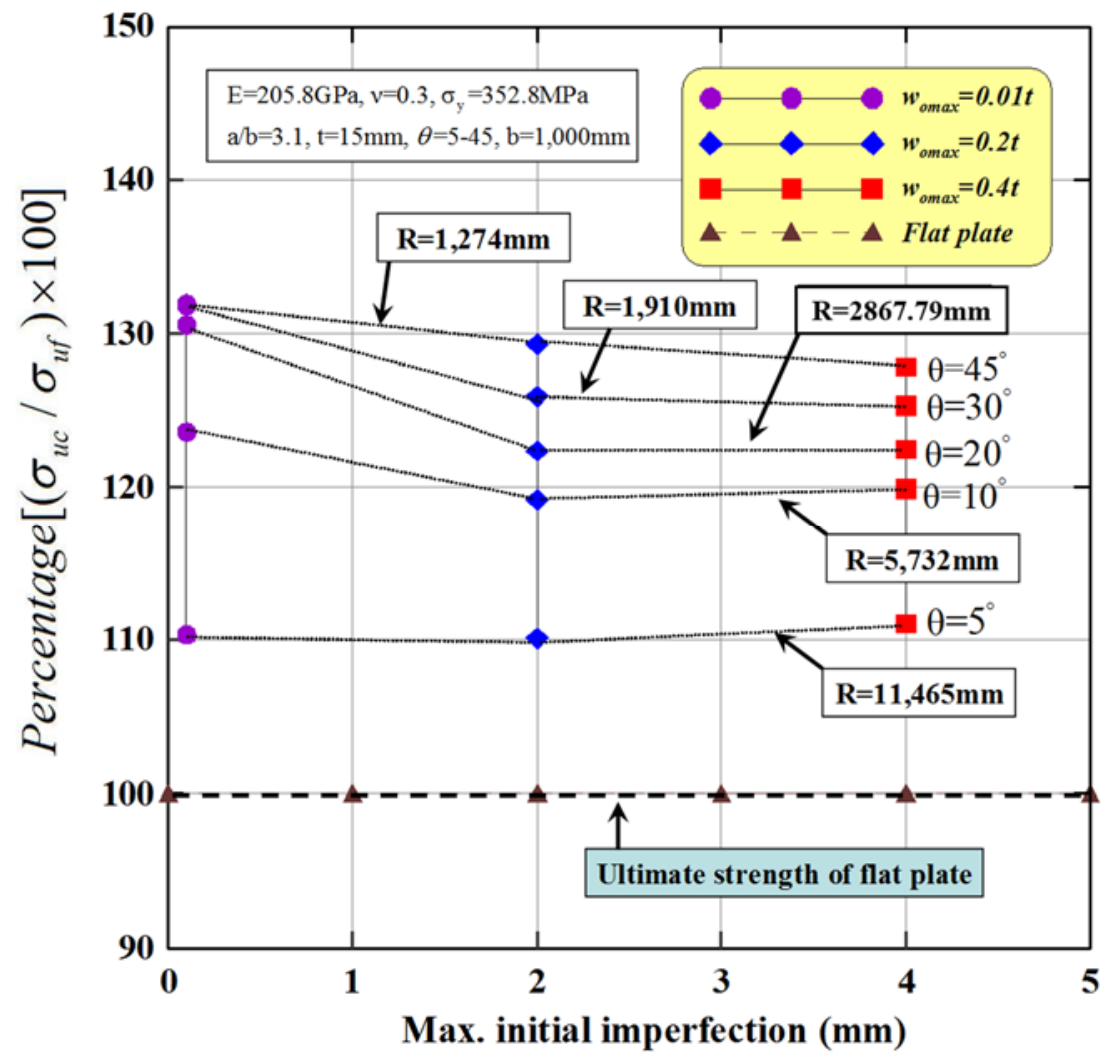

Fig. 6. The percentage relationship between the ultimate strength and various magnitudes of initial imperfection (deflection) between flat and curved plates subjected to axial load.

The ultimate strength tends to increase with increasing curvature while the amount of initial deflection decreases. When the flank angle is over 30 degrees, a small initial deflection (1\% of plate thickness) does not affect the ultimate strength, perhaps because over 30 degrees of curvature is closer to the behaviour of a cylindrical column at small initial deflection. Based on the numerical results, a thin-walled shell with a curvature is be expected to increase ultimate strength by about $10 \%$ to $30 \%$ minimum against the ultimate strength of the flat plate.

It is known that the safety margin of the ultimate strength of curvature can range from $10 \%$ to $32 \%$ under a compressive load. In other words, the existing design of curved plates tends to be conservative and is designed for safety. 


\subsection{Influence of the slenderness ratio}

To understanding the influence of the slenderness ratio, the ultimate strength is obtained for slenderness ratios $(\beta)$ ranging from 0.1 to 4.14 . The selected slenderness ratios are obtained by changing the thickness of the plate (i.e., 10-35 mm) while keeping the $1,000 \mathrm{~mm}$ breadth and the $3,000 \mathrm{~mm}$ length of the plate. The flank angles are considered to range from 5 to 45 degrees. In addition, the effect of the initial deflection for ultimate strength is considered at two levels [23]: slight $\left(0.025 \beta^{2} t\right)$ and average level $\left(0.1 \beta^{2} t\right)$.

Fig. 7 shows the ultimate strength varying slenderness ratio for curved plate $(a / b=3.0)$, which is considered to be slight, and the average level of the magnitude of the initial deflection varies from a flank angle of 5 to 45 degrees.

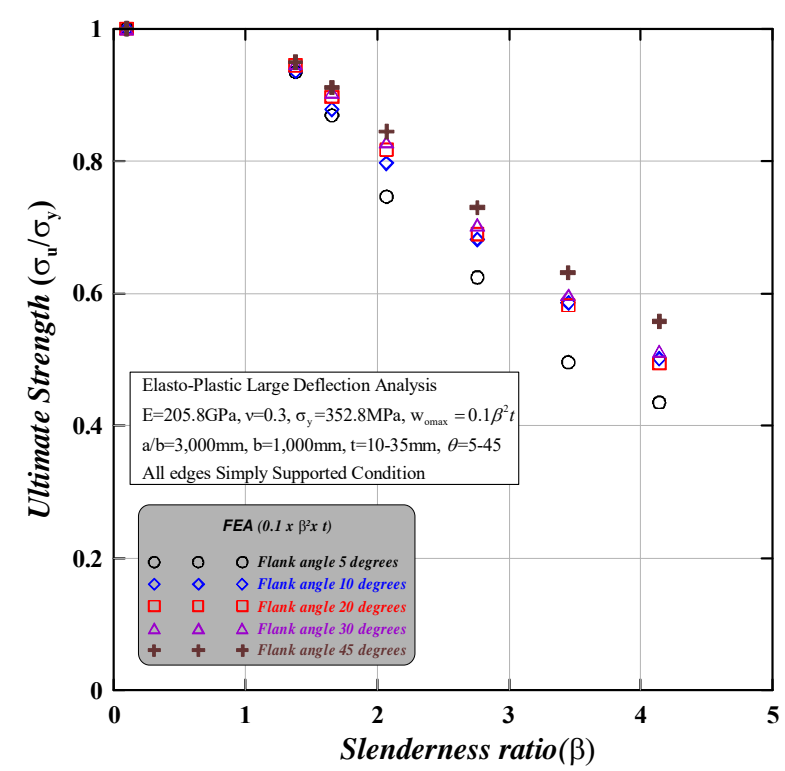

(a) Average initial deflection

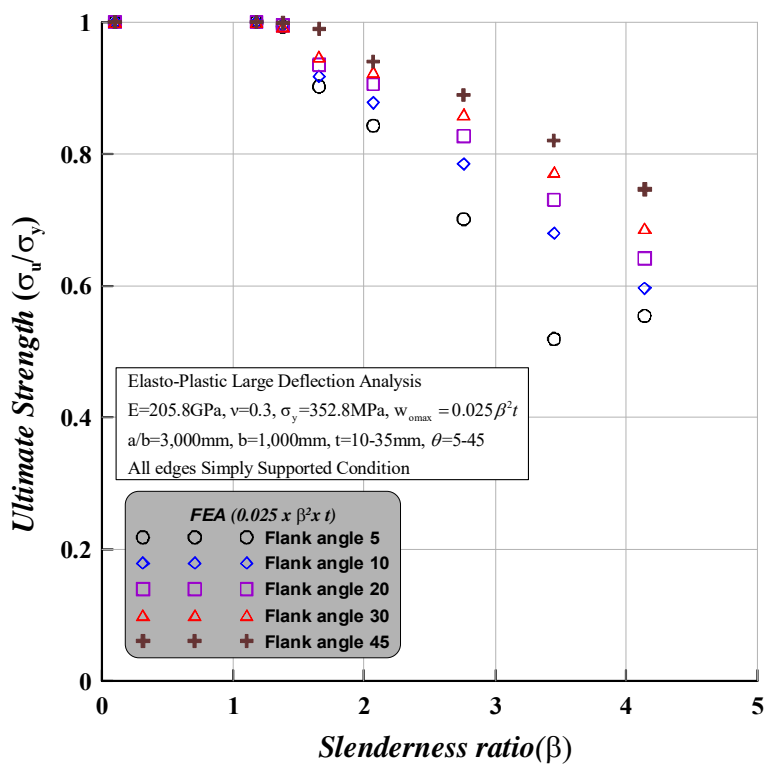

(b) Slight initial deflection

Fig. 7. The ultimate strength of curved plate varying slenderness ratio according to magnitude of imperfection

\subsubsection{Ranging from 0.1 to 1.18}

The slenderness ratio ranges from 0.1 to 4.14 . The ultimate strength tends to give similar values for both initial deflections. In particular, the ultimate strength of a flank angle of 5 degrees rapidly reduces over 1.65 of slenderness ratio compared to the other flank angles. The effect of the slenderness ratio of the curved plate heavily affects the ultimate strength, which is similar to a flat plate. The ultimate strength of all of the flank angles reaches the plate material yield strength from 0.1 to 1.38 of the slenderness ratio.

\subsubsection{Ranging from 1.18 to 4.14}

In particular, a curved plate with a flank angle of 5 degrees, a secondary buckling occurs at a slenderness ratio of 3.45, and the ultimate strength is evaluated to be low as comparing slenderness ratio of 4.14, because it affects the secondary buckling behaviour, which abruptly decreases the in-plane rigidity along to the longitudinal direction in the curved plate. The FE results are compared with the ultimate 
strength calculated by the DNV criterion [17], as shown in Fig. 8, which is current practice in industrial design. It can be seen that the current design formula gives a conservative estimation when the flank angle is smaller than 30 degrees and the magnitude of initial deflection is small. This gives an estimation for the curved plate of a flank angle of 30 degrees with the average magnitude of initial deflection, which is too unsafe. Therefore, the current design formula of a flat plate seems to give the lower bound of the ultimate strength for curved plates.

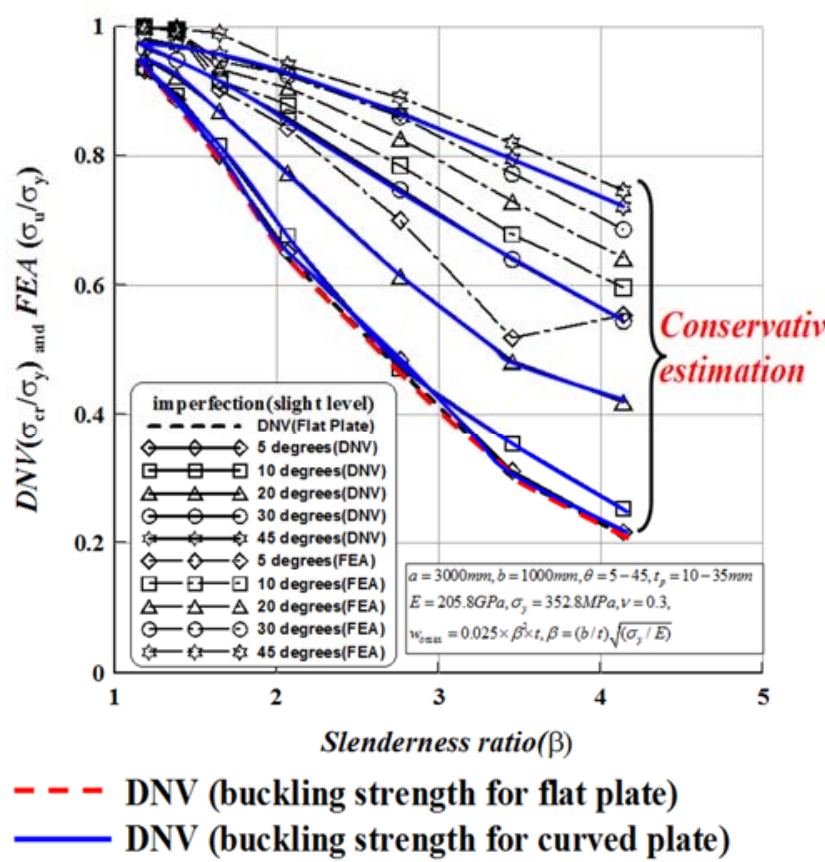

(a) Slight initial deflection

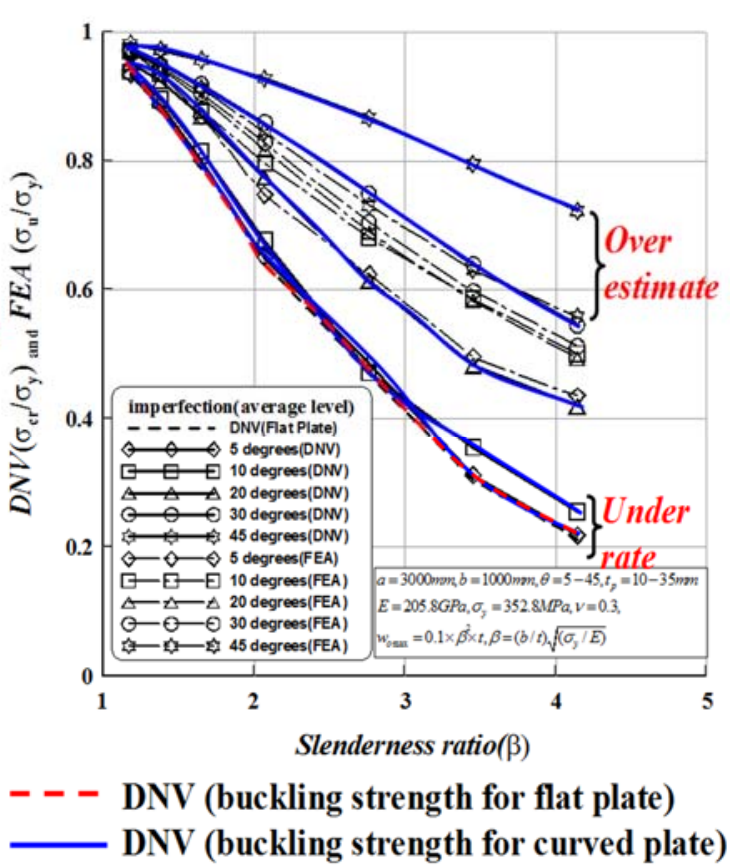

(b) Average initial deflection

Fig. 8. Comparison of the ultimate strength of curved plate calculated by FEM and estimation by DNV[17]

\subsection{Influence of the aspect ratio $(a / b)$}

The thickness of the plate is taken as $15 \mathrm{~mm}$, with a magnitude of initial deflection of $1 \%$ to the thickness. The influence of the plate aspect ratio $(a / b)$ for the ultimate strength of a cylindrical shell is considered to range from 1.0 to 6.0. Fig. 9 summarises the calculated results, which shows the effect of the aspect ratio on the ultimate strength of the curved plates with various flank angles and for circular cylinders subjected to axial load. The ultimate strength is sensitively affected due to the changing aspect ratio of curved plate with a flank angle of 5 degrees. However, for flank angles of more than 20 degrees, the aspect ratio is not affected. Thus, the effect of the aspect ratio can be neglected when the flank angle is over 20 degrees and with the same radius to thickness ratio, which can be predicted to have the maximum strength.

The details of our investigation of the 5 and 20 degrees of flank angles is shown in Fig. 10; it demonstrates the relationship of the ultimate strength against the aspect ratio with a buckling half-wave number. The thickness of the plate is taken as $15 \mathrm{~mm}$ and the magnitude of the initial deflection value 
is $40 \%$ to thickness. While changing the aspect ratios, the odd buckling half-wave collapse pattern appears from 1 to 9 .

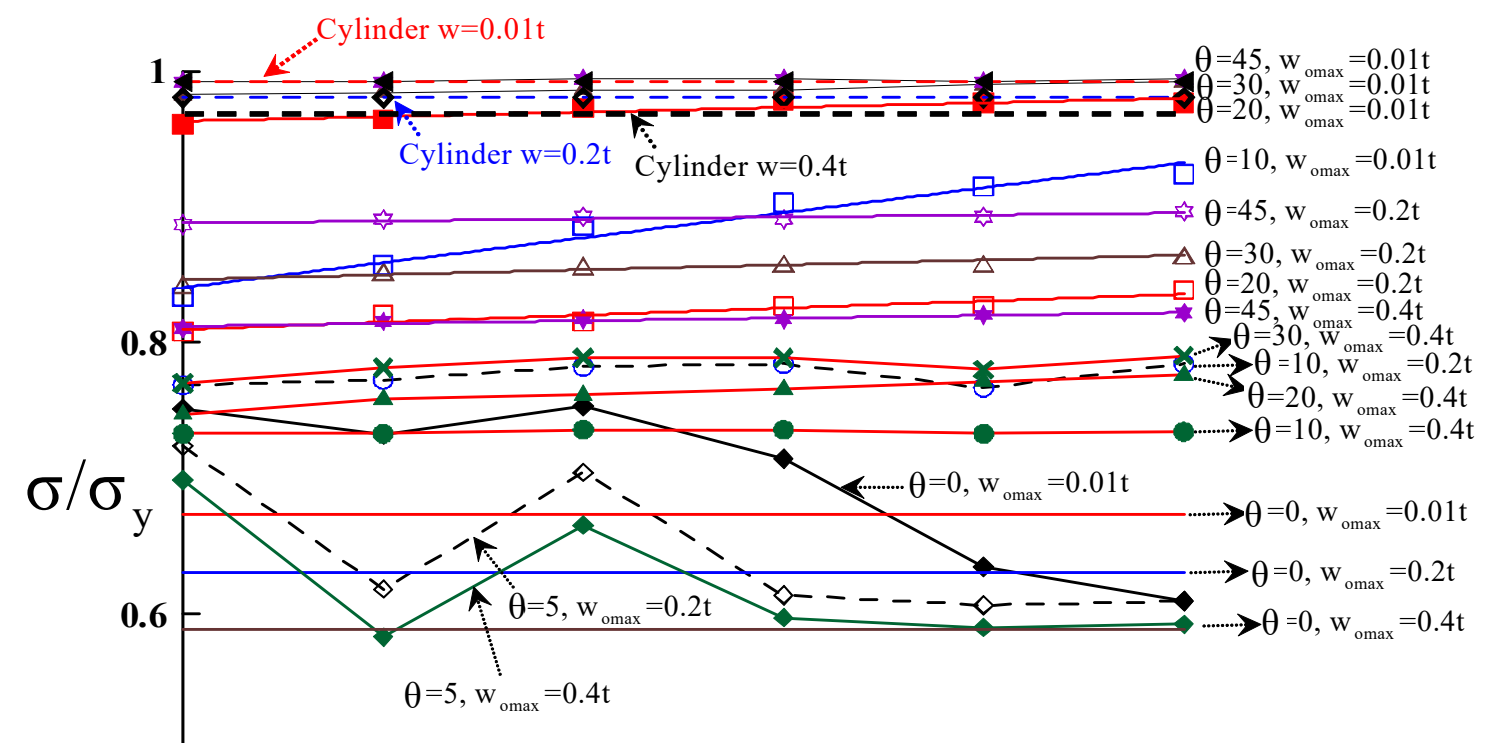

Elasto-Plastic Large Deflection Analysis

$\mathrm{E}=205.8 \mathrm{GPa}, v=0.3, \sigma_{\mathrm{y}}=352.8 \mathrm{MPa}, \mathrm{w}_{\text {omax }}=0.01 \mathrm{t}, 0.2 \mathrm{t}$ and $0.4 \mathrm{t}$

$0.4-a=1,000-6,000 \mathrm{~mm}, b=1,000 \mathrm{~mm}, \mathrm{t}=15 \mathrm{~mm}$

$\mathrm{L}=3,000 \mathrm{~mm}, \mathrm{R}=1,000 \mathrm{~mm}, \mathrm{t}=15 \mathrm{~mm}$

All edges Simply Supported Condition

\begin{tabular}{|llllll|}
\hline & 1 & 1 & 1 & 1 \\
\hline & 2 & 3 & 4 & 5 & 6
\end{tabular}

Fig. 9. A comparison of the ultimate strengths of a cylindrical shell with various aspect ratios under axial compression.

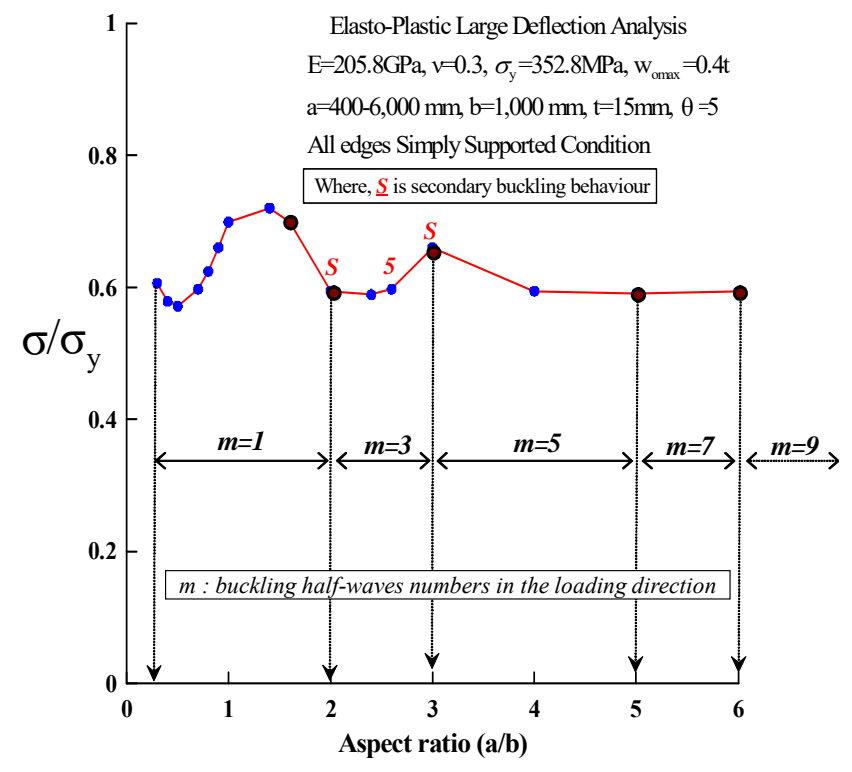

(a) 5 degrees

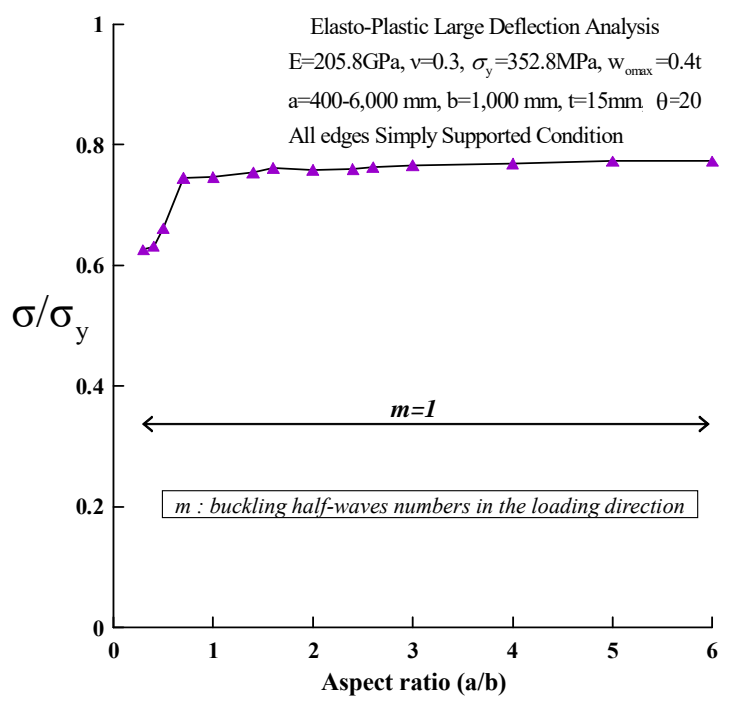

(b) 20 degrees

Fig. 10. Distribution of ultimate strength varying the aspect ratio for a curved plate with a flank angle of 5 and 20 degrees under axial compression 


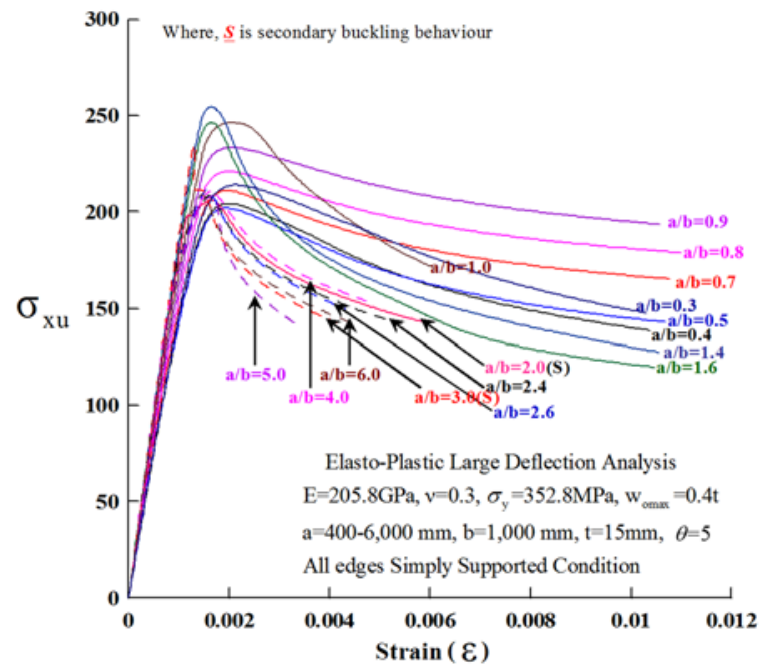

(a) $\theta=5$

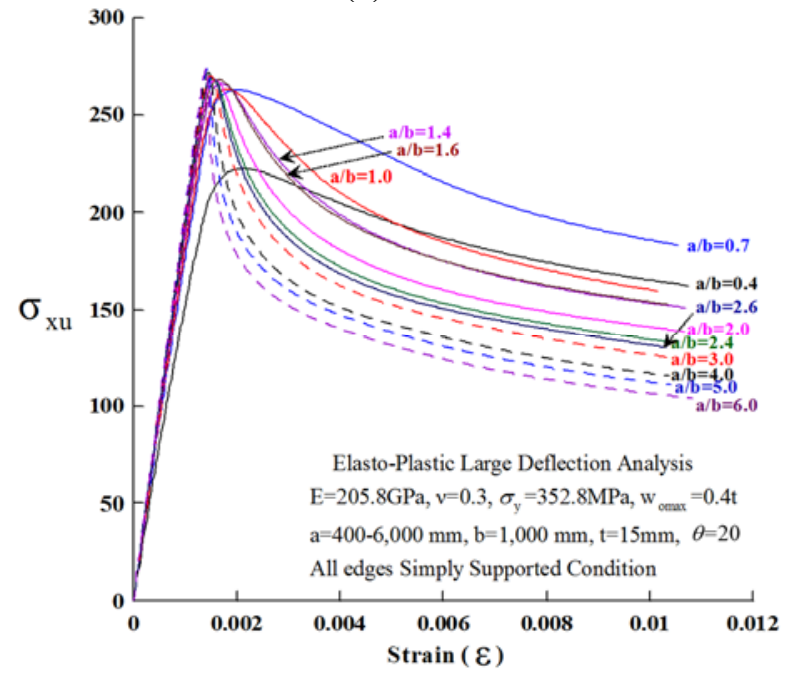

(c) $\theta=20$

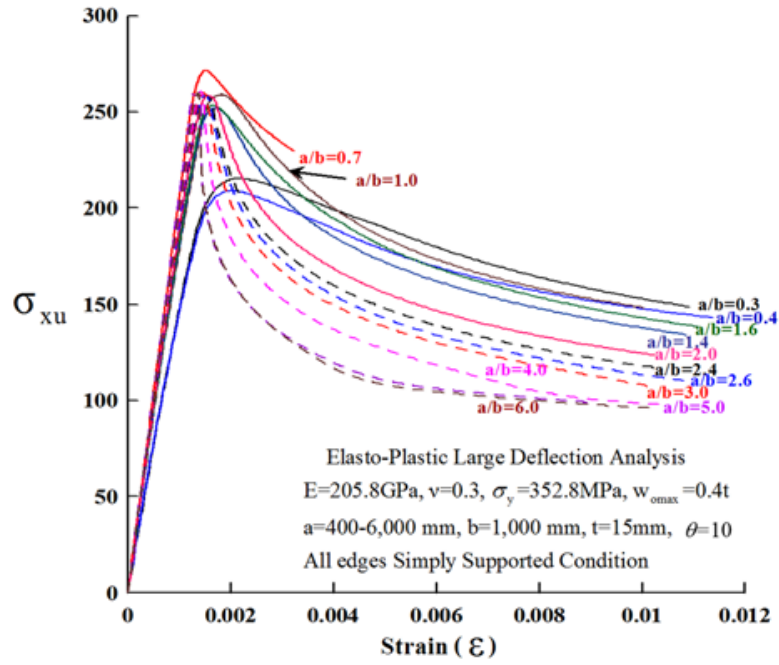

(b) $\theta=10$

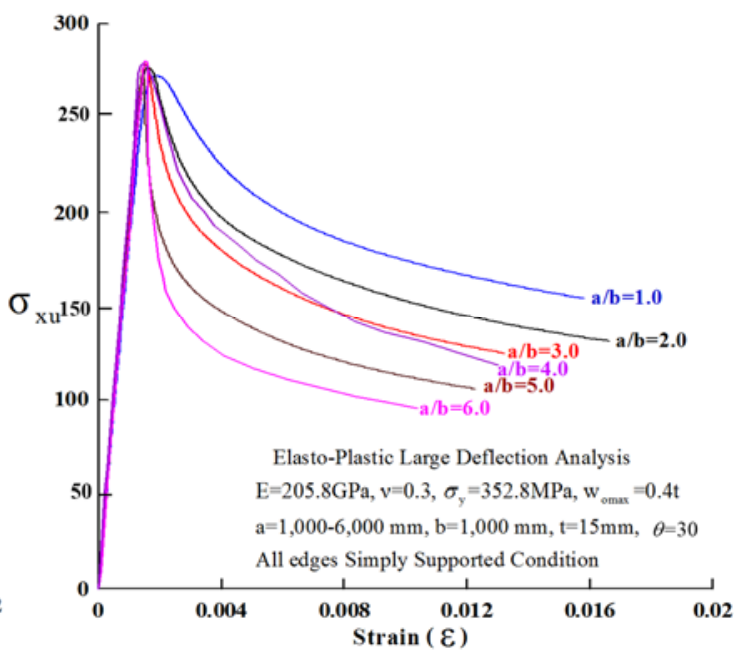

(d) $\theta=30$

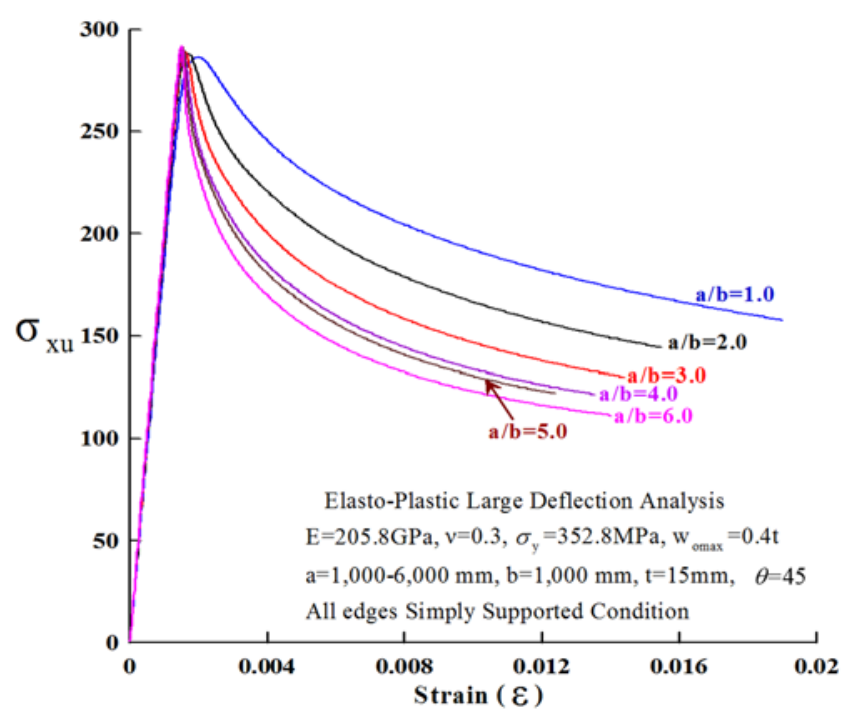

(e) $\theta=45$

Fig. 11. Comparison of stress and strain curves with varying aspect ratios and flank angles A secondary buckling behaviour is observed in the case of aspect ratios of 2.0 and 3.0. In the case of 
a flank angle of over 20 degrees, the same half-wave collapse pattern appears as for a flank angle of 5 degrees. This happens because the ultimate strength depends on the local collapse strength near the loading edges. Fig. 11 shows the structural behaviour for various aspect ratios for the curved plate with considered flank angles (5 to 45 degrees) and an initial deflection to thickness of $20 \%$. The highest ultimate strength is observed in an aspect ratio of 1.6. In an aspect ratio of below 1.0, there is a slightly reduced in-plane rigidity after ultimate strength.

It is also important to investigate deflection shape and distributed yield stress at the ultimate strength state of the curved plate for considered aspect ratio under axial compression. The buckling half-waves of a flat plate show the same amplitude of deflection and the ultimate strength is observed when the membrane stress components reach the yield condition at the unloaded edges of the plate. For the curved plate, the inward and outward half-waves show different amplitudes of deflection due to the curvature effect (i.e., 5 and 45 degrees), as shown in Fig. 13. The ultimate strength value appears when the yielding area spreads over the full width of the plate at the half-wave having the maximum amplitude of deflection.

\subsection{Secondary buckling behaviour}

Secondary buckling behaviour takes place for all cases, except for aspect ratio 1.0, in which the overestimated ultimate strength is better. Fig. 12 shows the relationship of the average stress and average strain of the curved plate with a flank angle of 5 and 45 degrees varying aspect ratio ranging from 1.0 to 6.0. The distribution of the ultimate strength shows an irregularity due to the occurrence of secondary buckling and the distribution of the ultimate strength scatters irregularly. When secondary buckling occurs, there is a rapid drop in the path and then it slightly goes up; however, it is lower than the secondary buckling strength, as shown in Fig. 12(a).

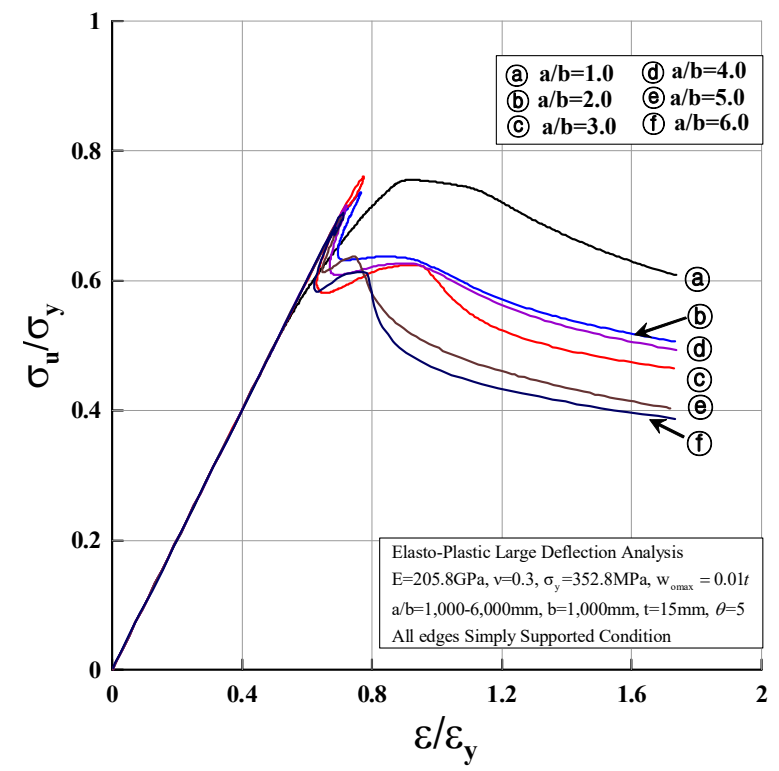

(a) 5 degrees

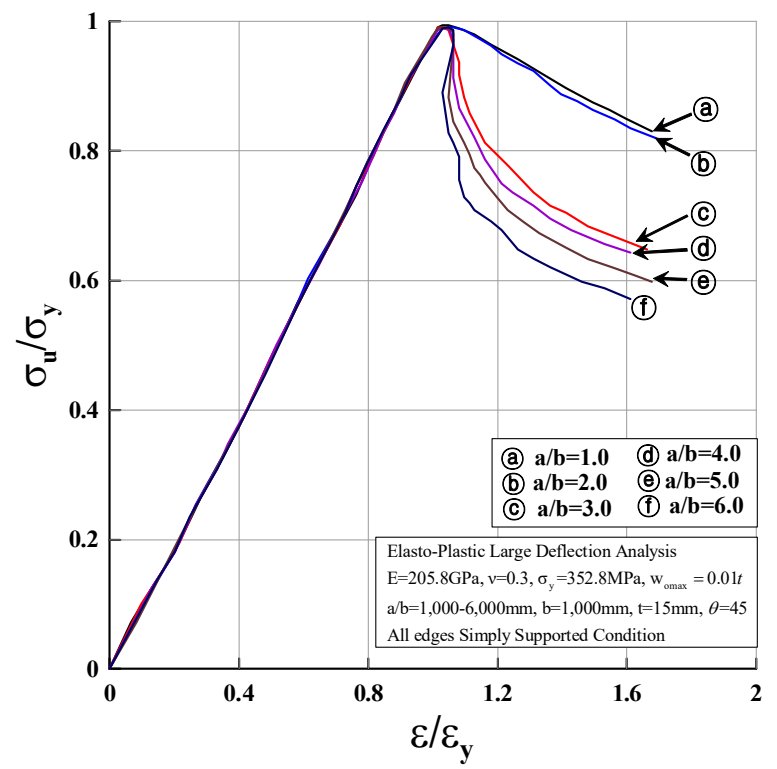

(b) 45 degrees

Fig. 12. Comparison of average stress and average strain curves varying aspect ratio with flank angles of 5 and 45 degrees subjected to axial load. 
In a flank angle of 45 degrees, the work softening or unloading behaviour started at $\varepsilon / \varepsilon_{y}=1.0$, together with the local plastic deformations in the post-ultimate range (as shown in Fig. 12(b)). Although the ultimate strength almost coincides with the yielding strength, a large discrepancy appears after the ultimate strength behaviour. Based on the numerical results, in-plane rigidity abruptly reduced after the ultimate strength over aspect ratio 3.0. As the aspect ratio increased, the in-plane rigidity gradually decreased.
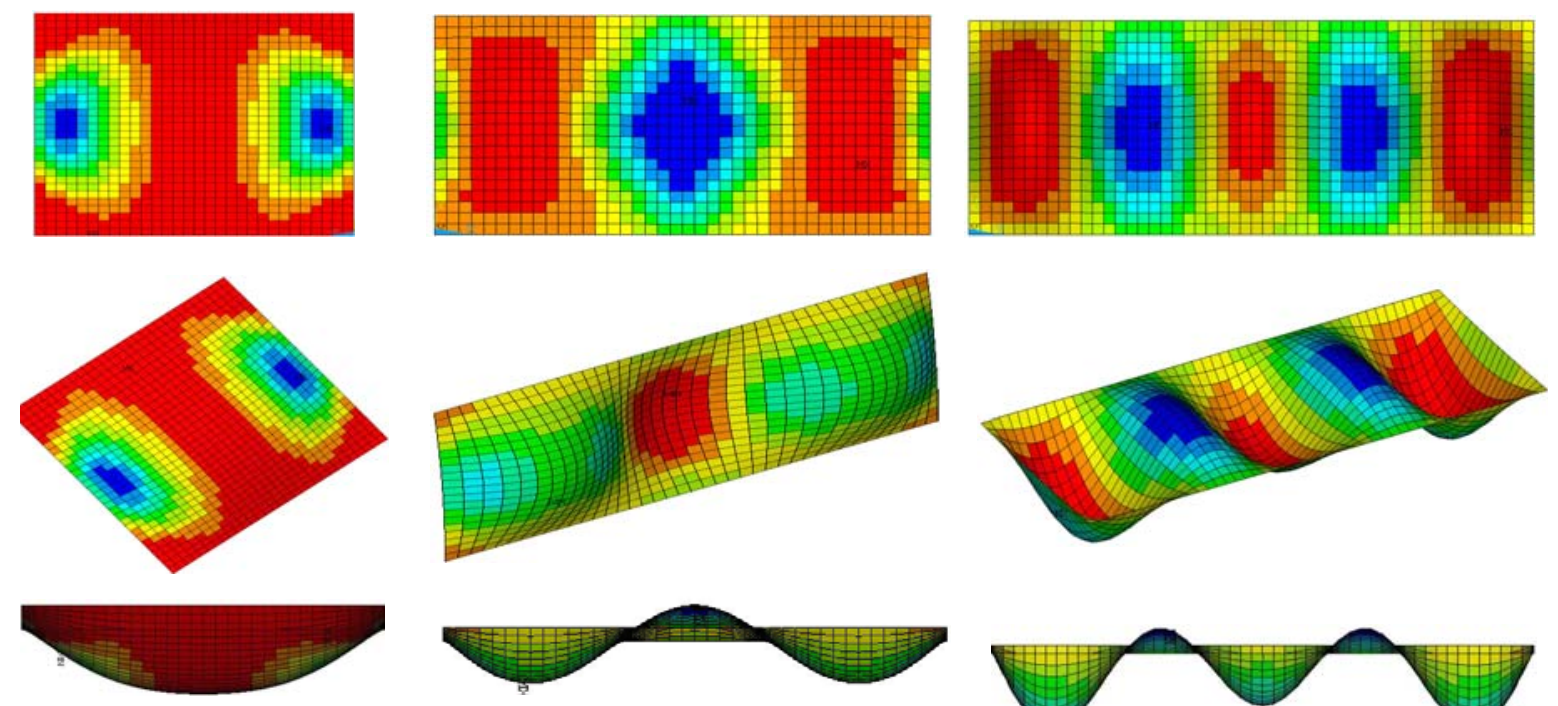

$\mathbf{a} / \mathbf{b}=\mathbf{1 . 0}$
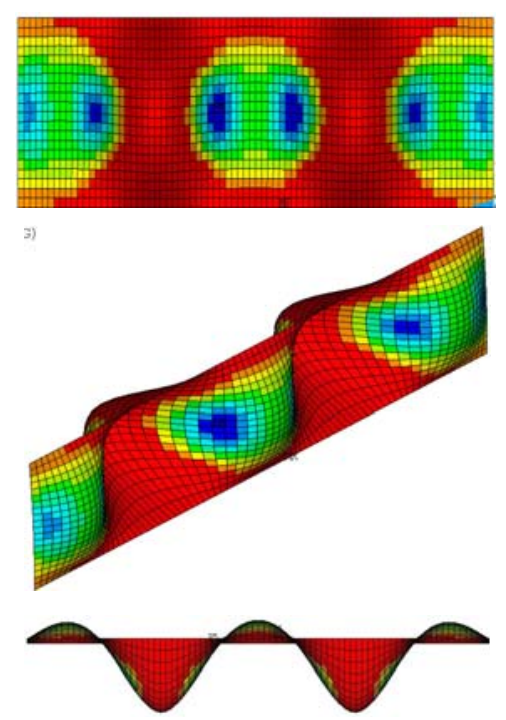

$\mathbf{a} / \mathbf{b}=\mathbf{4 . 0}$

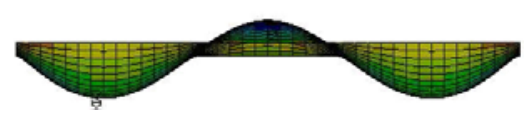

$\mathbf{a} / \mathbf{b}=\mathbf{2 . 0}$
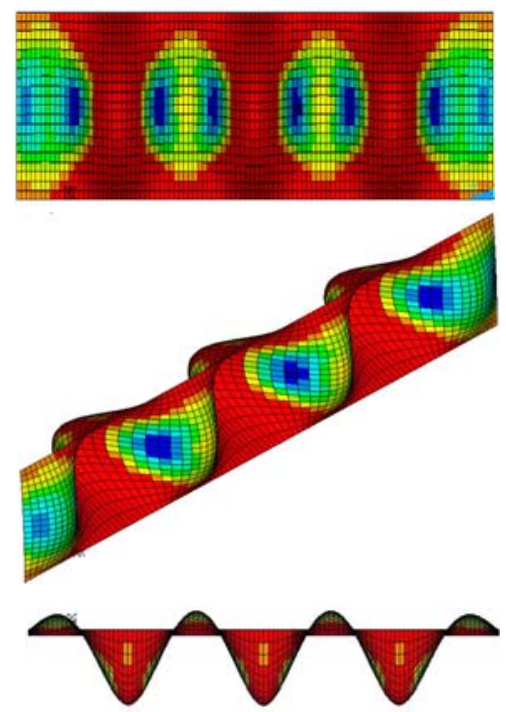

$\mathbf{a} / \mathbf{b}=\mathbf{5 . 0}$

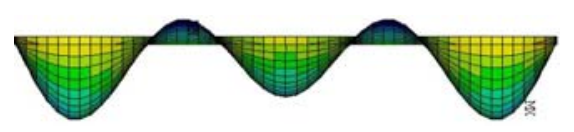

$\mathbf{a} / \mathbf{b}=\mathbf{3 . 0}$
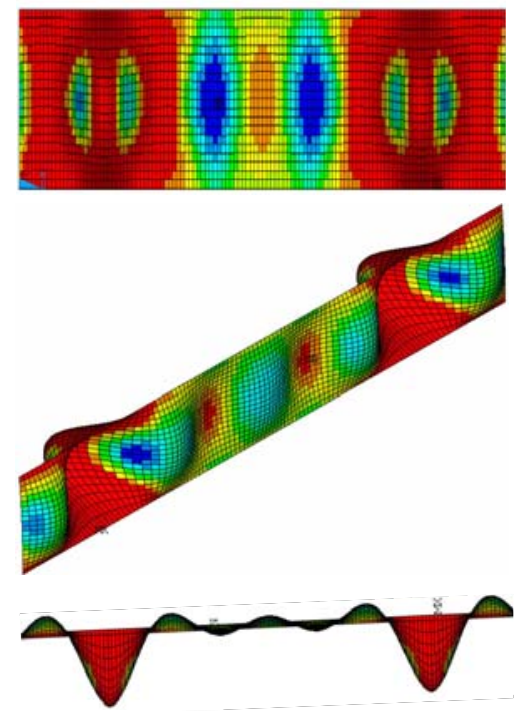

$\mathbf{a} / \mathbf{b}=\mathbf{6 . 0}$

Fig. 13(a). Deflection mode at ultimate strength for curved plate with a flank angle of 5 degrees and subjected to axial load $(\mathrm{a} / \mathrm{b}=1.0-6.0)$

Fig. 12(a) shows a collapse pattern and distribution of yield stress on the ultimate strength of the 
cylindrically curved plate with a flank angle of 5 degrees, a very small magnitude of initial imperfection, and aspect ratios from 1.0 to 6.0. This Fig. shows that the collapse pattern is very sensitive to a change in the aspect ratio. All of the aspect ratios have a non-symmetric buckling mode, except for aspect ratio 1.0 in which the distribution of yield stress is concentrated on an area of occurrence of larger deflection due to secondary buckling. If we simulate the nonlinear buckling procedure of the curved plate with a small flank angle considering a small initial imperfection, we will have to carefully consider the effect of the aspect ratio; however, it can be ignored if more than 20 degrees are reflected in the numerical results.

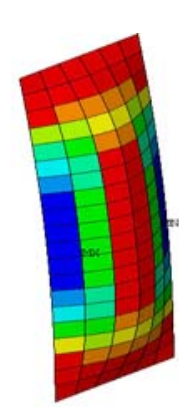

(a) $\mathbf{a} / \mathrm{b}=\mathbf{0 . 4}$

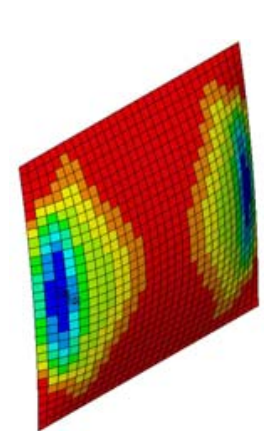

(b) $\mathbf{a} / \mathbf{b}=1.0$

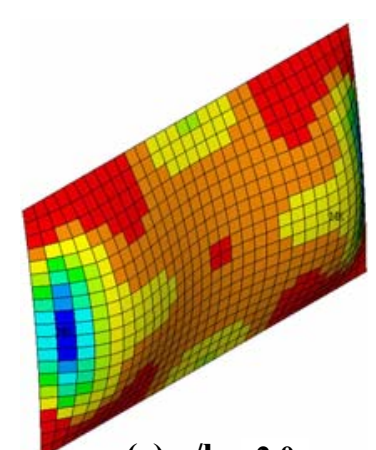

(c) $\mathbf{a} / \mathbf{b}=\mathbf{2 . 0}$

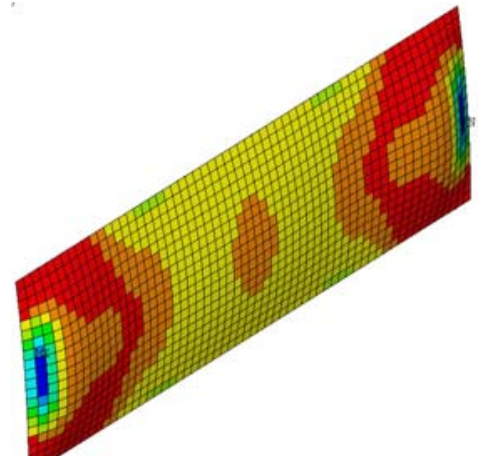

(d) $\mathbf{a} / \mathbf{b}=\mathbf{3 . 0}$

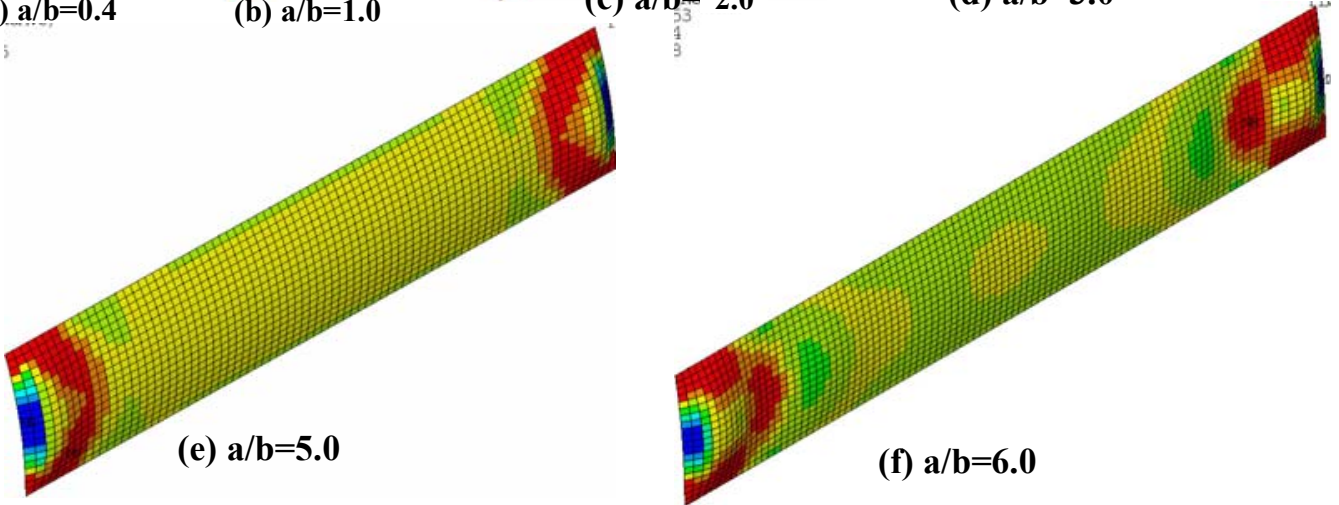

Fig. 13(b) Deflection mode at ultimate strength for a curved plate with a flank angle of 45 degrees subjected to an axial load $(\mathrm{a} / \mathrm{b}=1.0-6.0)$

Fig. 13(b) illustrates the collapse pattern and distribution of yield stress on the ultimate strength of a cylindrically curved plate with a flank angle of 45 degrees, a very small magnitude of initial imperfection, and aspect ratios from 1.0 to 6.0. The collapse pattern induced buckling is very similar when varying the aspect ratio. In particular, aspect ratios over 3.0 show a local plastic deflection on the circumferential edges.

The load carrying capability of all structures is dependent on their geometry, material properties, and boundary conditions. Uniquely, cylindrical shell structures when subjected to axial load are especially sensitive to initial imperfections, as can be seen in the previous results. Therefore, geometric imperfections should be observed with the second buckling behaviour.

The calculated ultimate strength is plotted against the magnitude of geometrical deflection while varying the increase of the flank angle, as shown in Fig.14(a). To find if this holds true in the case of 
cylindrically curved plates, an alternative series of elasto-plastic analysis is performed by changing the maximum magnitude of the initial deflection. In these calculations, initial imperfections from $0.5 \%$ to $30 \%$ plate thickness are considered. A cylindrically curved plate under axial compression is also sensitive to the magnitude of initial deflection. The lowest ultimate strength is evaluated when the flank angle is 5 degrees for the thin plate $(t=10 \mathrm{~mm})$ because secondary buckling will change the deflection shape.

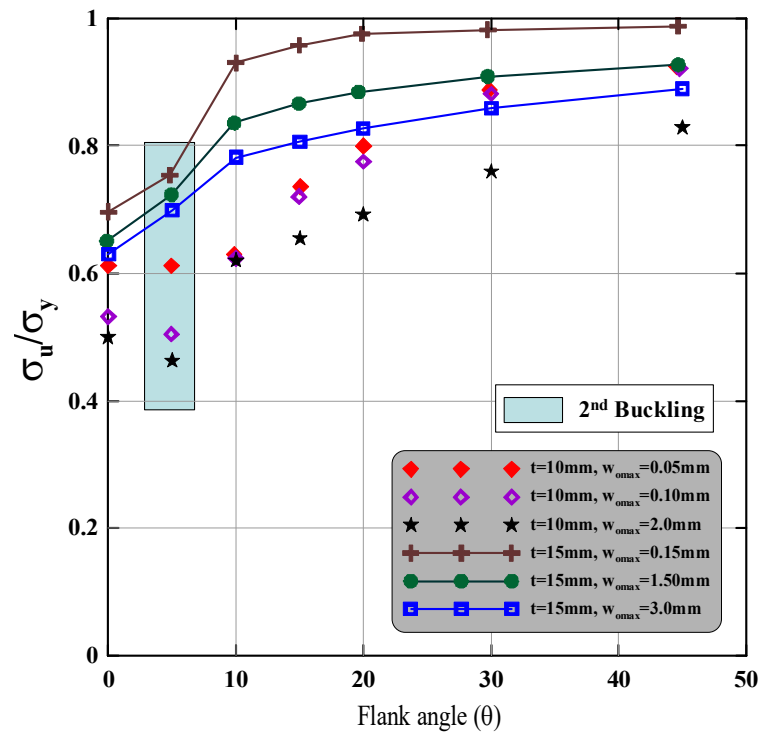

(a)

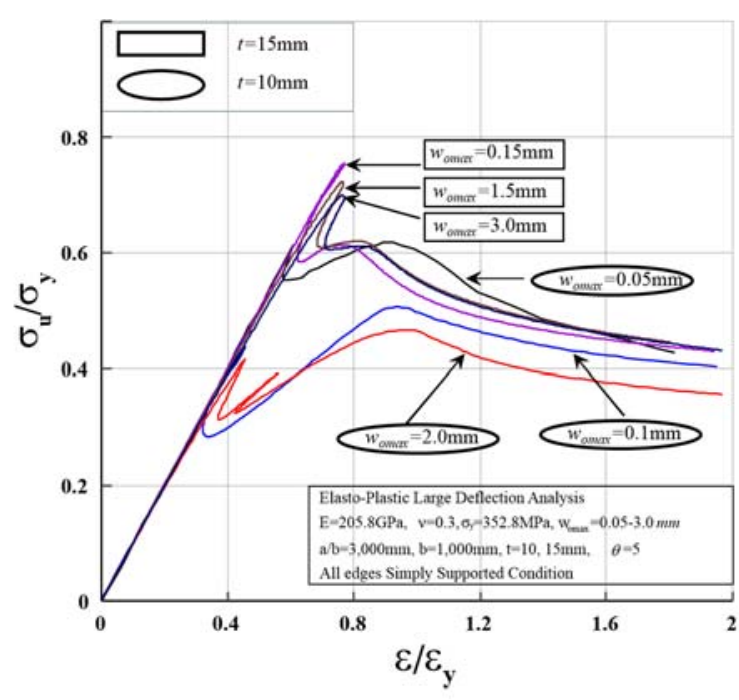

(b)

Fig. 14. Ultimate strength against curvature for curved plates with various magnitudes of initial deflection.

Fig. 14(b) shows that, with a flank angle of 5 degrees, the average stress and strain curves increase with the magnitude of initial imperfection of the curved plate. Secondary buckling behaviour is observed among all cases, regardless of the magnitude of the initial imperfection value. In particular, the ultimate strength of a thin plate $(\mathrm{t}=10 \mathrm{~mm})$ is estimated to be lower than that of a flat plate because of secondary buckling accompanied by unloading behaviour. If we wish to examine the ultimate strength of a curved plate with a small flank angle, then we have to carefully consider secondary buckling behaviour.

\subsection{Influence of boundary condition}

To investigate the ultimate strength characteristics of a cylindrically curved plate with different boundary conditions, two kinds of boundary conditions are included in one frame of the local FE model, such as being simply supported and clamped when subjected to longitudinal compression.

Fig. 15 shows the relationships of the average stress and average strain of an unstiffened curved plate with a flank angle of 5 degrees, considering two kinds of boundary conditions under axial compression. A summary of the numerical results is shown in Fig. 16 and Appendix (Table A4-A6) . 
As we expected, the ultimate strength for clamped condition is generally larger than that for the simply supported condition. The ultimate strength of the considered thin plates $\left(t=8 \mathrm{~mm}, \theta=30^{\circ}\right)$ is smaller than for the simply supported condition. This happened because the edge restraint of the clamped condition affected the secondary buckling condition.

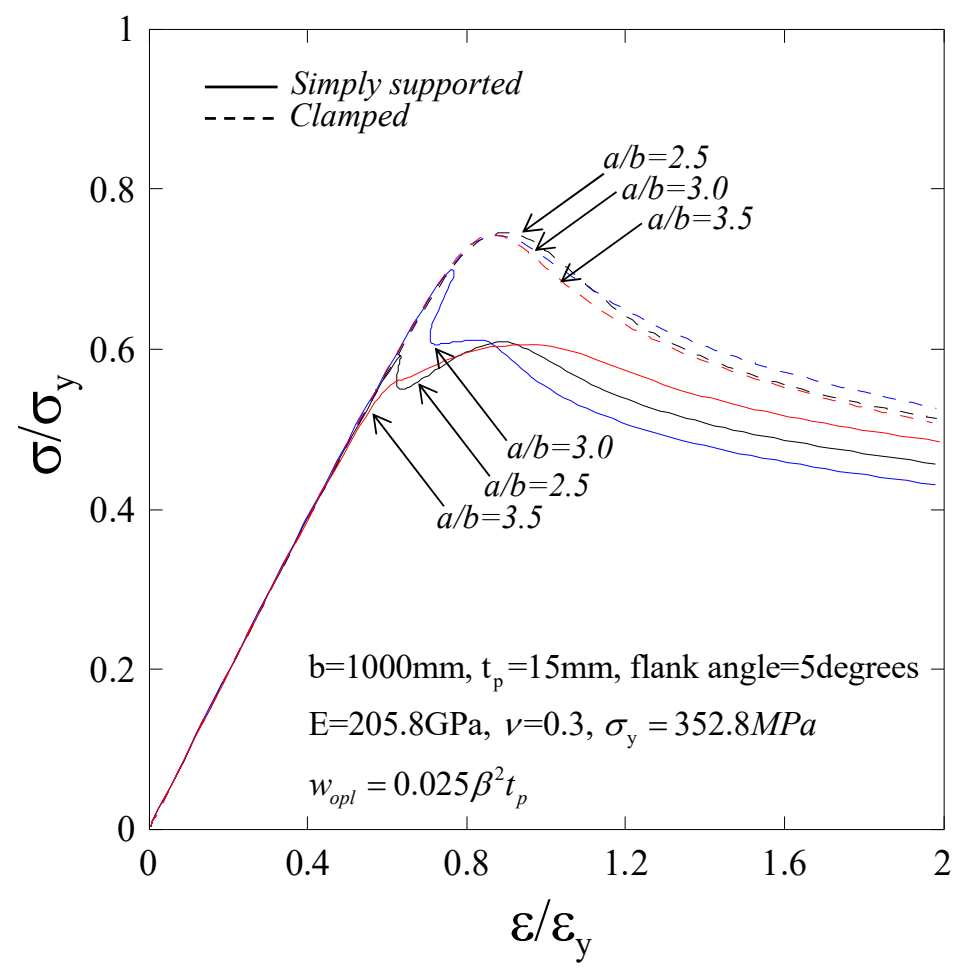

Fig. 15. A comparison of the average stress and average strain of the curved plate with two kinds of boundary conditions under axial compression (thickness $=15 \mathrm{~mm}$, flank angle $=5$ degrees)

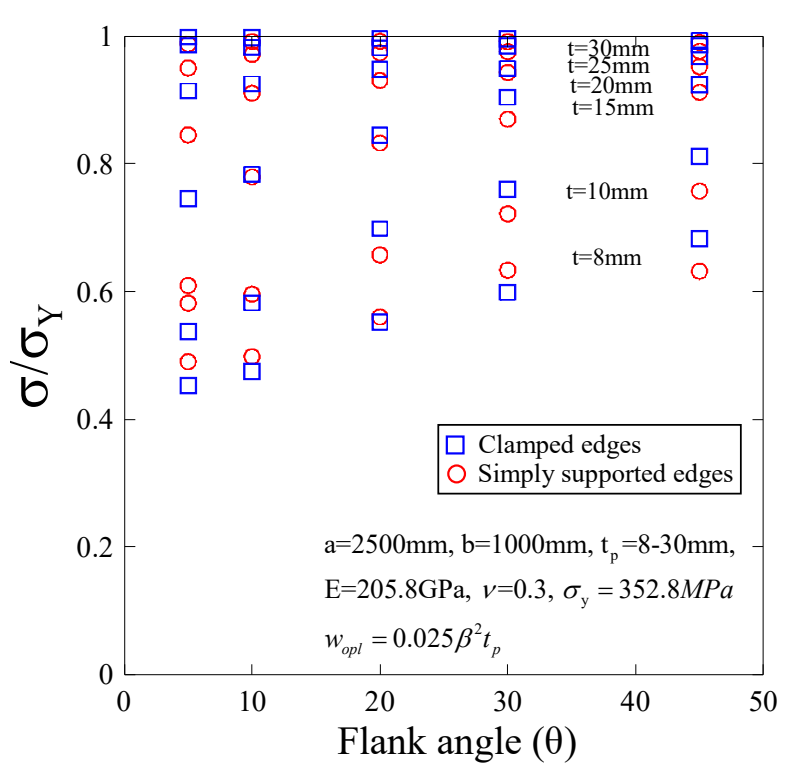

(a) $\mathrm{a} / \mathrm{b}=2.5$

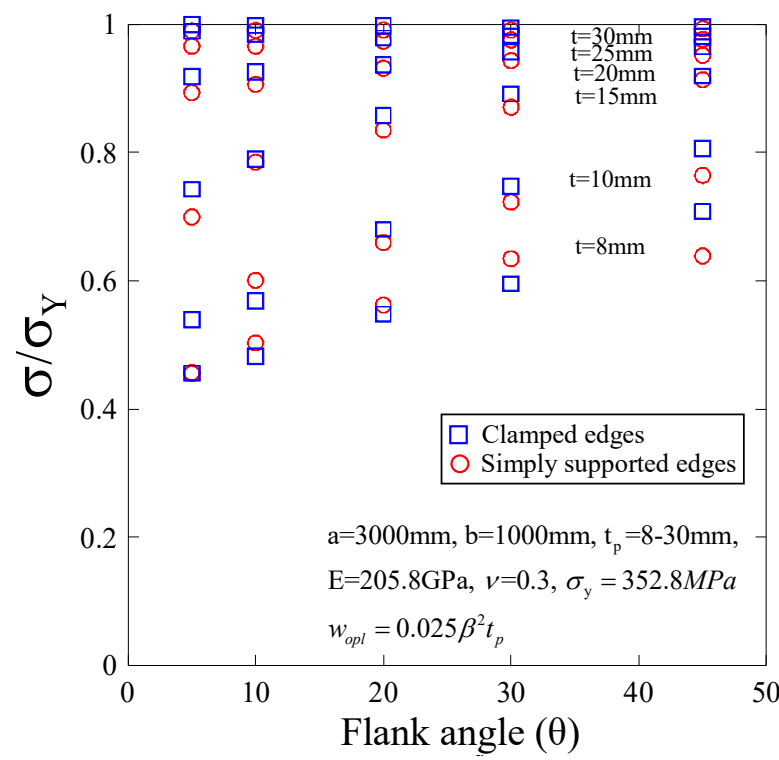

(b) $\mathrm{a} / \mathrm{b}=3.0$ 


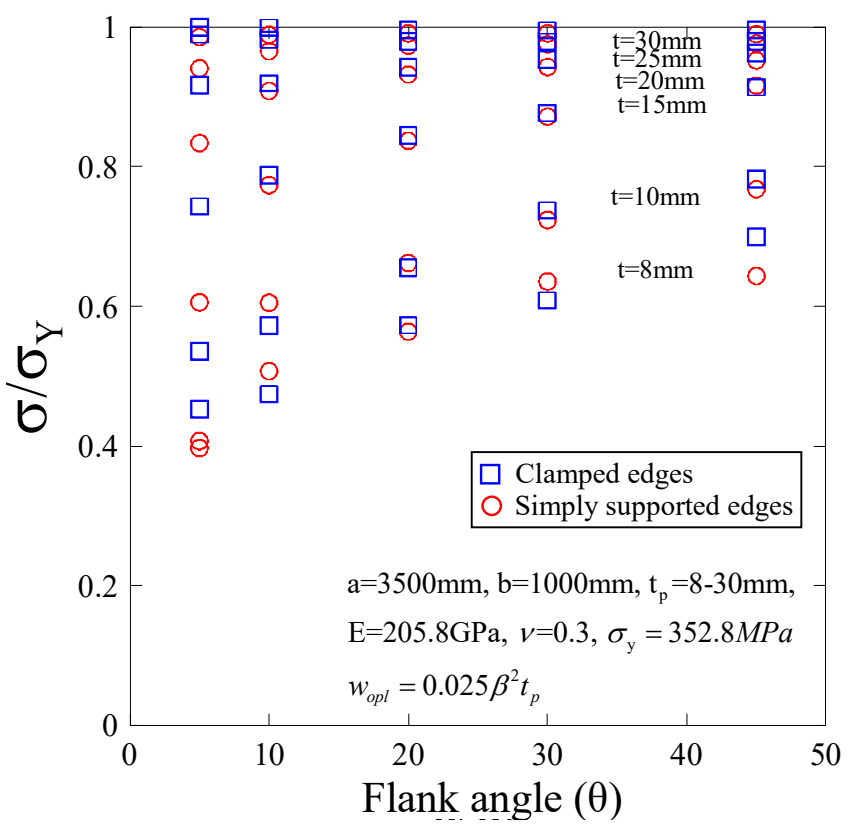

(c) $\mathrm{a} / \mathrm{b}=3.5$

Fig. 16. A comparison of the average stress and flank angle varying thickness of a plate with two kinds of boundary conditions under axial compression

The aspect ratio also varied from 2.5 to 3.5 . The ultimate strength of a curved plate in a clamped condition was not affected by an increase of the aspect ratio due to the effects of the restraint. We considered aspect ratios of 2.5,3.0, and 3.5 and the ultimate strength for the clamped case is, on average, only $17 \%, 30.8 \%, 28.6 \%$ larger than the ultimate strength for the simply supported case. In addition, the ultimate strength for the clamped case is, on average, only $1.4 \%, 1.9 \%$, and $2.7 \%$ larger than the ultimate strength for the simply supported case. Therefore, the simply supported condition shows very sensitive behaviour with accompanied secondary buckling. The latter cases also underestimate the ultimate strength compared with the clamped condition.

\section{The modified design formulae}

In this study, the design formulae were proposed to estimate the ultimate strength of a cylindrically curved plate under a compressive axial load. The formulae are derived from a numerical database of 288 cases (see Appendix) and the applied curved plate slenderness ratios are as follows:

For a simply supported flat plate, the Faulkner's formula [31] is widely used to estimate the ultimate strength, as given by:

$$
\left\{\begin{array}{ll}
\frac{\sigma_{U}}{\sigma_{Y}}=1.0 & \text { for } \beta<1.0 \\
\frac{\sigma_{U}}{\sigma_{Y}}=\frac{2.0}{\beta}-\frac{1.0}{\beta^{2}} & \text { for } \beta>1.0
\end{array}\right\}
$$


where $\sigma_{U}$ is the ultimate strength, $\sigma_{Y}$ is the yield strength and $\beta$ is the slenderness ratio of

$$
\beta=\frac{b}{t} \sqrt{\frac{\sigma_{Y}}{E}}
$$

The slenderness ratio $(\beta)$ of Eq. (5) has a physical meaning as a square root of the ratio of the yield strength $\left(\sigma_{Y}\right)$ to the elasto buckling strength $\left(\sigma_{E}\right)$, as found from the following relationship;

$$
\begin{gathered}
\sqrt{\frac{\sigma_{Y}}{\sigma_{E}}}=\sqrt{\frac{\sigma_{Y}}{\frac{k E \pi^{2}}{12\left(1-v^{2}\right)}\left(\frac{t}{b}\right)^{2}}}=\sqrt{\frac{12\left(1-v^{2}\right)}{k \pi^{2}}} \frac{b}{t} \sqrt{\frac{\sigma_{Y}}{E}}=\sqrt{\frac{12\left(1-v^{2}\right)}{k \pi^{2}}} \beta \\
\text { where } \sigma_{E}=\frac{k E \pi^{2}}{12\left(1-v^{2}\right)}\left(\frac{t}{b}\right)^{2}
\end{gathered}
$$

On this basis, a new definition of the slenderness parameter, $\beta^{\prime}$ is introduced by considering the ratio of the elastic-plastic buckling and ultimate strength of a flat plate, $\sigma_{C R}^{F}$ and $\sigma_{U}^{F}$ and that of a curved plate, $\sigma_{C R}^{C}$ and $\sigma_{U}^{C}$ obtained by eigen-value analysis with plastic correction, as given by:

$$
\beta^{\prime}=\beta \times \sqrt{\sigma_{C R}^{F} / \sigma_{C R}^{C}} \quad \text { and } / \text { or } \quad \beta^{\prime}=\beta \times \sqrt{\sigma_{U}^{F} / \sigma_{U}^{C}}
$$

The ultimate strength of a curved plate is then estimated by substituting $\beta^{\prime}$ of Eq. (7) into the modified Faulkner's formula of ultimate strength of a flat plate. This implies that a curved plate that has a larger buckling/ultimate strength than a flat plate is regarded as an equivalent flat plate with reduced slenderness or increased plate thickness.

Fig. 17 shows the relationships between the new definition of the slenderness parameter and the ultimate strength of a curved plate with an average magnitude of initial imperfection, in addition to the modified Faulkner's formula of ultimate strength of a flat plate. The aspect ratio varies from 1.0 to 5.0 and the flank angle also changes from 5 to 45 degrees. For a flank angle below 10 degrees, where the collapse of a curved plate takes place in several half-wave buckling modes, similarly to the collapse of a flat plate, the FEM results plotted against $\beta^{\prime}$ are in good agreement with modified Faulkner's formula. However, for a larger flank angle, the agreement is worse. This may be because of the development of longitudinal cylindrical deformation, and the effect of transverse membrane stress cannot be neglected.

It can be concluded that the combination of the slenderness parameter $\beta^{\prime}$ and the modified Faulkner's formula may provide a simple method to estimate the ultimate strength of a curved plate under longitudinal compression when the flank angle is relatively small.

The accuracy of the modified Faulkner's formula plotted against $\beta^{\prime}$ was checked by a comparison with finite element solutions for flank angles between 5 and 10 degrees, as shown in Fig. 18. The solid marks show cases with the occurrence of secondary buckling. It is noted that the means and standard deviations of the error in the modified Faulkner's formula against FEA are 0.768 and 0.175 , respectively, for the slight magnitude of initial deflection. In addition, Faulkner's formula correlated with mean $=0.769$ and standard deviation $=0.178$ against the ultimate strength obtained by FEA with average 
magnitude of initial deflection.

Fig. 19(a) shows correlation of the elastic-plastic buckling strength which is calculated by DNV [17] and FE results of curved plate under axial compression. The thickness of plating is varies from $10 \mathrm{~mm}$ to $30 \mathrm{~mm}$ and flank angle also change from 5 to 45 degrees. The aspect ratio is fixed 3.0. It can be observed that it is quite different buckling strength in comparison of DNV and FEM. Fig. 19(b) shows correlation of elastic-plastic buckling strength with plastic correction by DNV and ultimate strength. The design curve is given big differences compared with FE results. The reason is that the current design formulae are not fully considered curved plate characteristic both buckling and ultimate strength. The developed formulas are applicable to curved plates with an aspect ratio of between 1.0 and 5.0 in the fixed width of $1,000 \mathrm{~mm}$. Thicknesses are considered from $8 \mathrm{~mm}$ to $40 \mathrm{~mm}$, and the maximum initial deflection of the curved plate is classified into two types, slight and average level from Smith's formula.

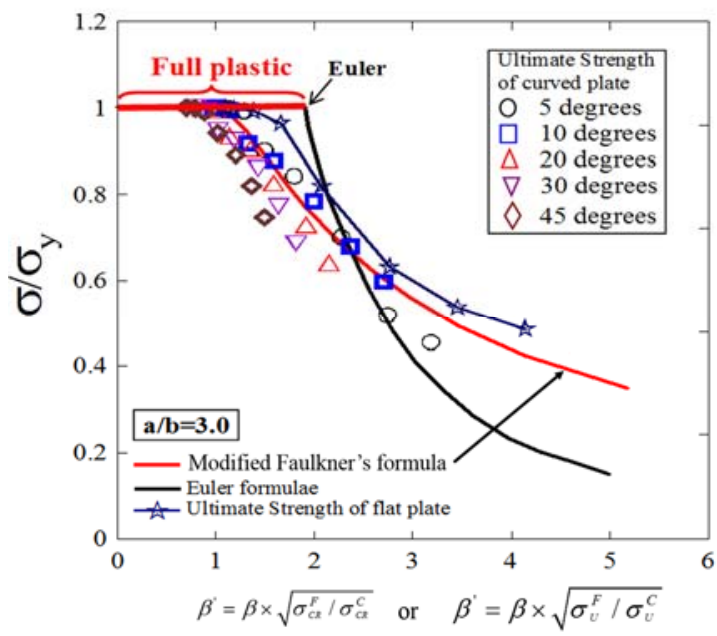

(a) $\mathrm{a} / \mathrm{b}=3.0$

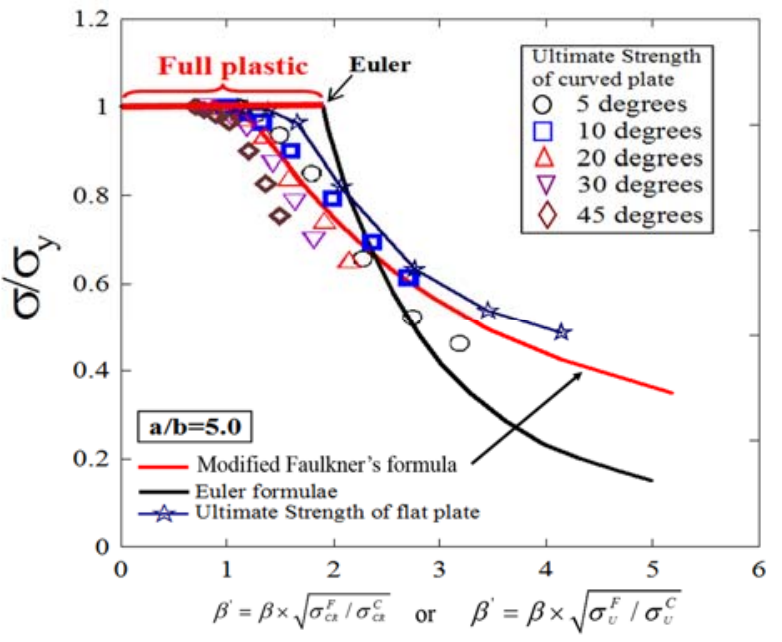

(b) $\mathrm{a} / \mathrm{b}=5.0$

Fig. 17. Variation of the ultimate strength of the curved plates with new function of the reduced slenderness ratio, $\mathrm{a} / \mathrm{b}=3.0$ and 5.0 (average magnitude of initial imperfection)
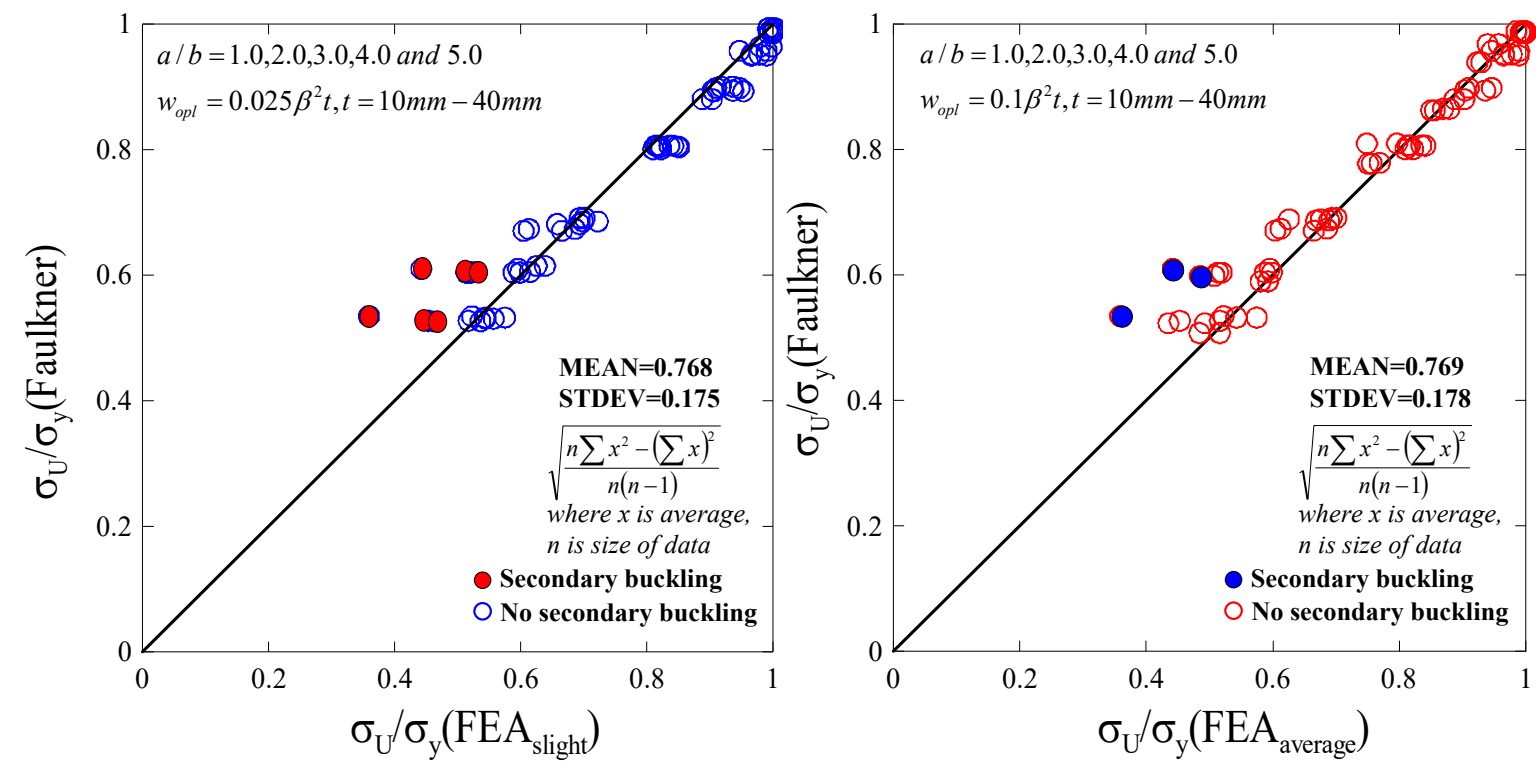
Fig. 18. Correlation of the modified Faulkner's formula with ultimate strength obtained by FEM of curved plates with flank angles of 5 and 10 degrees

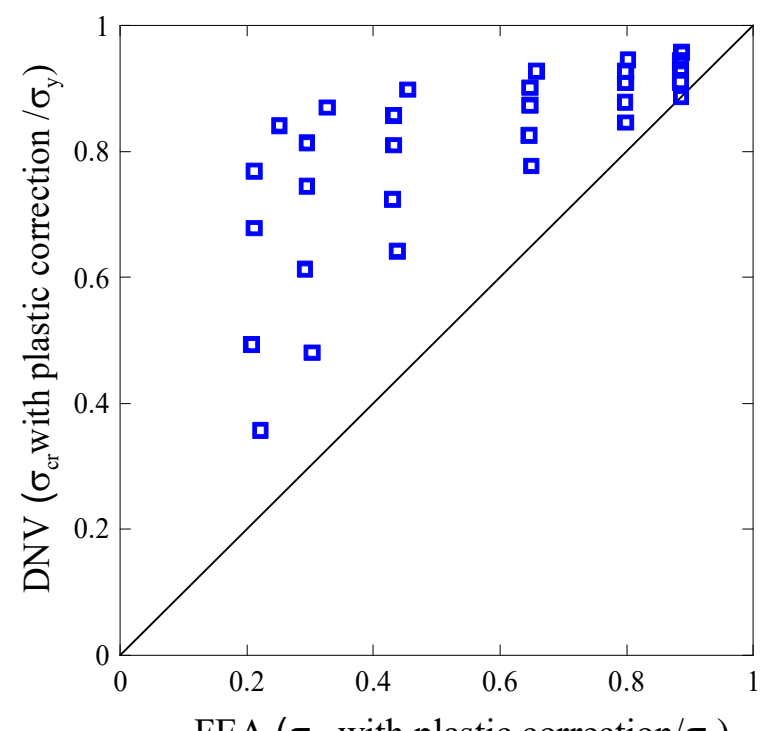

FEA $\left(\sigma_{\mathrm{cr}}\right.$ with plastic correction $\left./ \sigma_{\mathrm{y}}\right)$

(a) Elastic-plastic buckling strength

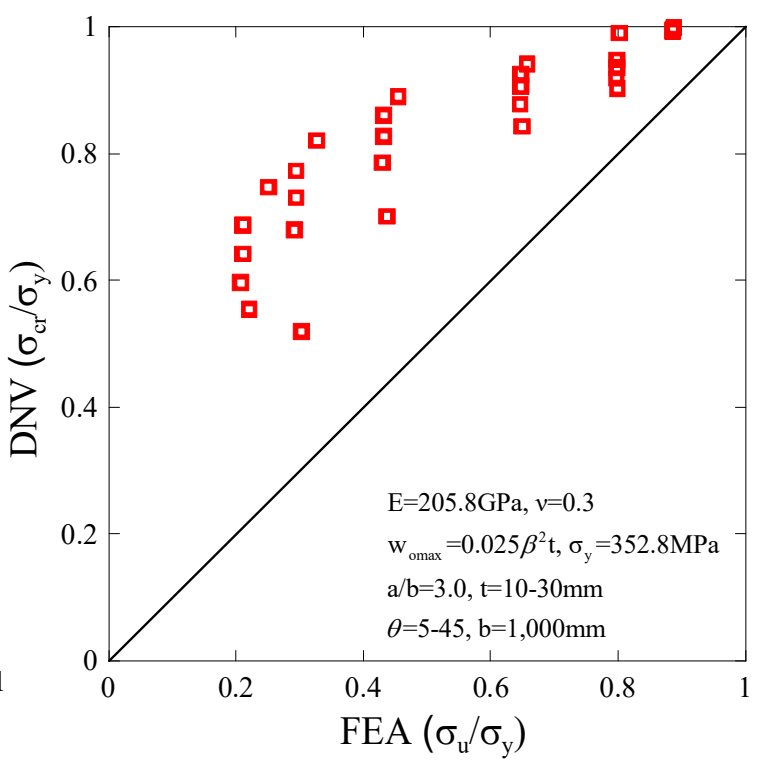

(b) Ultimate strength

Fig. 19. Correlation of DNV design formulae [17] with FEA results for curved plates

The elastic buckling strength of longitudinally stiffened cylindrical shells by DNV is given by:

$$
f_{E}=C \frac{\pi^{2} E}{12\left(1-v^{2}\right)}\left(\frac{t}{l}\right)^{2}
$$

The reduced buckling coefficient may be calculated as:

$$
C=\psi \sqrt{1+\left(\frac{\rho \xi}{\psi}\right)^{2}}
$$

The values for $\psi, \xi$ and $\rho$ are given in Table 1 for the most important load cases.

Table 1 Buckling coefficients for stiffened cylindrical shells, mode b) Panel stiffener buckling

\begin{tabular}{|c|c|c|c|}
\hline & $\psi$ & $\xi$ & $\rho$ \\
\hline Axial stress & $\frac{1+\alpha_{C}}{1+\frac{A}{s_{e}}}$ & $0.702 Z_{l}$ & 0.5 \\
\hline $\begin{array}{c}\text { Torsion and } \\
\text { Shear stress }\end{array}$ & $5.34+1.82\left(\frac{l}{s}\right)^{4 / 3} \alpha_{C}^{1 / 3}$ & $0.856 Z_{l}^{3 / 4}$ & 0.6 \\
\hline $\begin{array}{c}\text { Lateral } \\
\text { Pressure }\end{array}$ & $2\left(1+\sqrt{1+\alpha_{C}}\right)$ & $1.04 \sqrt{Z_{l}}$ & 0.6 \\
\hline
\end{tabular}

where

$$
\begin{gathered}
Z_{l}=\frac{l^{2}}{r t} \sqrt{1-v^{2}} \\
\alpha_{C}=\frac{12\left(1-v^{2}\right) I_{s e f}}{s t^{3}}
\end{gathered}
$$

$A=$ area of one stiffener, exclusive shell plate 
$I_{\text {sef }}=$ moment of inertia of longitudinal stiffener including effective shell width $S_{e}$

The curvature coefficient used in the DNV Eqn.(10) is designed to predict the buckling strength of cylindrical cylinders and curvature coefficient does not properly evaluate the buckling behaviour of the curved plate with partial curvature. The current design formulae are overly conservative, and the results do not consider the characteristics of the curved plates. Therefore, a reasonable curvature coefficient should be newly developed through nonlinear FEA results.

\section{Concluding Remarks}

This study presents details of a non-linear FE analysis which was used to investigate structural behaviour including the bucking and ultimate strength of curved plates. The results obtained indicate the effects of curvature, initial deflection, slenderness ratio and aspect ratio, boundary conditions and secondary buckling behaviour.

The effect of the slenderness ratio of the curved plate heavily affects ultimate strength, which is similar to a flat plate. A secondary buckling occurs at a slenderness ratio of 3.45 and a flank angle of 5 degrees. The ultimate strength is evaluated to be low compared with slenderness ratio of 4.14, because it affects secondary buckling behaviour, which abruptly decreases the in-plane rigidity along the longitudinal direction in the curved plate. The ultimate strength is sensitively affected due to the changing aspect ratio of a curved plate with a flank angle of 5 degrees.

A modified Faulkner's formula is developed for predicting the ultimate strength of a curved plate under axial compression. The accuracy of the modified Faulkner's formula plotted against was checked by a comparison with finite element solutions. The developed formulas are applicable to curved plates with an aspect ratio of between 1.0 and 5.0 in the fixed width of $1,000 \mathrm{~mm}$. Thicknesses are considered from $8 \mathrm{~mm}$ to $40 \mathrm{~mm}$, and the maximum initial deflection of the curved plate is classified into two types, slight and average level from Smith's formula.

\section{Acknowledgement}

This research was supported by Basic Science Research Program through the National Research Foundation of Korea (NRF) funded by the Ministry of Science, ICT \& Future Planning (NRF2017R1A2B4004891)

\section{References}

[1] Featherston CA (2000). The use of finite element analysis in the examination of instability in flat plates and curved panels under compression and shear. International Journal of Non-Linear Mechanics, 35(3): 515-529

[2] Featherston CA (2003). Imperfection sensitivity of curved panels under combined compression 
and shear. International Journal of Non-Linear Mechanics, 38: 225238.

[3] Featherston CA (2012). Geometric imperfection sensitivity of curved pan-els under combined compression and in-plane bending - A study us-ing adaptive meshing and DIC. Strain, 48: 286295.

[4] Martins JP, Simões L, Reis A (2013). Eigenvalue analysis of cylindrically curved panels under compressive stresses - extension of rules from EN 1993-1-5, Thin-Walled Structures 68: 183-194.

[5] Martins JP, Silvestre N, L. Simões L (2016). Energy-based analytical model to predict the elastic critical behaviour of curved panels, Journal of Constructional Steel Research, 127: 165-175.

[6] Martins JP, Simões L, Reis A (2014). Ultimate load of cylindrically curved panels under in plane compression and bending - Extension of rules from EN 1993 1 5, Thin-Walled Structures, 77: 3647.

[7] Khanh LT, Laurence D, Cyril D, Karam S (2012). Stability of curved panels under uniform axial Compression. Journal of Constructional Steel Research. 69: 30-38.

[8] Maeno Y, Yamaguchi H, Fujii Y, Yao T (2004). Buckling/plastic collapse behaviour and strength of bilge circle and its contribution to ultimate longitudinal strength of ship's hull girder. Proceedings of the International Offshore and Polar Engineering Conference, Toulon, France, 2328 May 2004.

[9] Yumura K, Katsura S, Ijima K, Yao T (2005). Simulation of buckling collapse behaviour of cylindrically curved plates under axial compression. Proceedings of TEAM Conference.

[10]Park HJ, Cho SR, Chung JN, Lee DB (2005). Ultimate strength analysis of curved stiffened shell of container bilge strake. Proceedings of the Annual Autumn Meeting, SNAK, Yongiin, Korea: $189-195$.

[11]Kwen YW, Park YI, Paik JK, Lee JM (2004). Buckling and ultimate strength characteristics for ship curved plate structures. Proceedings of the Annual Autumn Meeting, SNAK, Sancheong, Korea: 351-356.

[12] Cho SR, Park HZ, Kim HS, Seo JS (2007). Experimental and numerical investigations on the ultimate strength of curved stiffened plates. Proceedings of the 10th International Symposium on Practical Design of Ships and other Floating Structures, Houston, Texas: 453-60.

[13]Park JS, Yumura K, Katsura S, Kazuhiro I, Tetsuya Y (2006). Buckling and post-buckling behaviour of cylindrically curved plates under axial compression. Proceedings of the Society of Naval Architects and Ocean Engineers, Japan.

[14]Park JS, Iijima K, Yao T (2007). Estimation of buckling and ultimate strength for curved plates with and without stiffeners under axial compressive load. TEAM 2007, Yokohama. Japan.

[15] Park JS, Iijima K, Yao T (2008). Characteristics of buckling and ultimate strength and collapse behaviour of cylindrically curved plates subjected to axial compression. Applied Mechanics and 
Materials, ISSN: 1660-9336: 1195-1200.

[16] Kim JH, Park JS, Lee KH, Kim JH, Kim MH, Lee JM (2014). Computational analysis and design formula development for the design of curved plates for ships and offshore structures. Structural Engineering and Mechanics, 49(6): 705-726.

[17]DNV (2002). Buckling strength of shells. Recommended practice DNV-RP-C202.

[18] Tran K, Davaine L, Douthe C, Sab K (2012). Stability of curved panels under uniform axial compression. Journal of Constructional Steel Research, 69(1): 30-38.

[19] Tran KL, Douthe C, Sab K, Dallot J, Davaine L (2014). Buckling of stiffened curved panels under uniform axial compression. Journal of Constructional Steel Research, 103: 140-147.

[20] Tran KL, Douthe C, Sab K, Dallot J, Davaine L (2014). A preliminary design formula for the strength of stiffened curved panels by design of experiment method. Thin-Walled Structures, 79: $129-137$.

[21] Yao T, Fujikobo M, Yanagihara D (1998). On loading and boundary conditions for buckling/plastic collapse analysis of continuous stiffened plate by FEM. 12th Asian Technical Exchange and Advisory Meeting on Marine Structures, Kanazawa: 305-314.

[22] Seo JK, Song CH, Park JS, Paik JK (2016). Nonlinear structural behaviour and design formulae for calculating the ultimate strength of stiffened curved plates under axial compression. ThinWalled Structures, 107: 1-7.

[23] Paik JK (2018). Ultimate limit state analysis and design of steel-plated structures. Chichester, UK: Wiley.

[24]Paik JK, Thayamballi AK (2007). Ship-shaped offshore installations: design, building, and operation. Cambridge, UK: Cambridge University Press.

[25]Benson S, Downes J, Dow RS (2011). Ultimate strength characteristics of aluminium plates for high-speed vessels. Ships and Offshore Structures, 6(1-2): 67-80.

[26] Smith CS, Davidson PC, Chapman JC and Dowling PJ (1988). Strength and stiffness of ships' plating under in-plane compression and tension. RINA Transactions, 130: 227-296.

[27]Zhanga S (2016). A review and study on ultimate strength of steel plates and stiffened panels in axial compression. Ships and Offshore Structures, 11(1): 81-91.

[28]ANSYS (2010). 10.0 User's Manual: Chapter 4 Introduction to Material Nonlinearities. ANSYS Inc., USA.

[29] Paik JK, Seo JK (2009). Nonlinear finite element method models for ultimate strength analysis of steel stiffened-plate structures under combined biaxial compression and lateral pressure actionsPartI: Plate elements. Thin-Walled Structures, 47: 1008-1017.

[30]Faulkner D. (1975). "A review of effective plating for use in the analysis of stiffened plating in bending and compression," Journal of Ship Research, 19(1), 1-17. 


\section{APPENDIX}

Table A1. Comparison of elastic-plastic buckling stresses for curved plate with simply supported and clamped edges $(\mathrm{a} / \mathrm{b}=2.5)$

\begin{tabular}{|c|c|c|c|c|c|c|}
\hline $\mathrm{a}$ & $\mathrm{b}$ & $\mathrm{t}$ & $\theta$ & $\begin{array}{l}\text { Simply Supported } \\
\left(\sigma_{C R_{-} s S}\right)\end{array}$ & $\begin{array}{l}\text { Clamped } \\
\left(\sigma_{C R_{-} C L}\right)\end{array}$ & $\frac{\sigma_{C R_{-} S S}}{\sigma_{C R_{-} C L}} \times 100(\%)$ \\
\hline \multirow{5}{*}{2500} & \multirow{5}{*}{1000} & \multirow{5}{*}{8} & 5 & 0.2454 & 0.5659 & 43.4 \\
\hline & & & 10 & 0.3563 & 0.6161 & 57.8 \\
\hline & & & 20 & 0.6091 & 0.7608 & 80.1 \\
\hline & & & 30 & 0.7598 & 0.8368 & 90.8 \\
\hline & & & 45 & 0.8407 & 0.8898 & 94.5 \\
\hline \multirow{5}{*}{2500} & \multirow{5}{*}{1000} & \multirow{5}{*}{10} & 5 & 0.3499 & 0.5202 & 67.3 \\
\hline & & & 10 & 0.4861 & 0.6706 & 72.5 \\
\hline & & & 20 & 0.6981 & 0.8110 & 86.1 \\
\hline & & & 30 & 0.8097 & 0.8697 & 93.1 \\
\hline & & & 45 & 0.8793 & 0.9116 & 96.5 \\
\hline \multirow{5}{*}{2500} & \multirow{5}{*}{1000} & \multirow{5}{*}{15} & 5 & 0.6249 & 0.7576 & 82.5 \\
\hline & & & 10 & 0.7197 & 0.8137 & 88.5 \\
\hline & & & 20 & 0.8176 & 0.8819 & 92.7 \\
\hline & & & 30 & 0.8775 & 0.9157 & 95.8 \\
\hline & & & 45 & 0.9277 & 0.9420 & 98.5 \\
\hline \multirow{5}{*}{2500} & \multirow{5}{*}{1000} & \multirow{5}{*}{20} & 5 & 0.7663 & 0.8566 & 89.5 \\
\hline & & & 10 & 0.8220 & 0.8792 & 93.5 \\
\hline & & & 20 & 0.8758 & 0.9172 & 95.5 \\
\hline & & & 30 & 0.9131 & 0.9398 & 97.2 \\
\hline & & & 45 & 0.9472 & 0.9573 & 98.9 \\
\hline \multirow{5}{*}{2500} & \multirow{5}{*}{1000} & \multirow{5}{*}{25} & 5 & 0.8414 & 0.9050 & 93.0 \\
\hline & & & 10 & 0.8747 & 0.9162 & 95.5 \\
\hline & & & 20 & 0.9100 & 0.9386 & 97.0 \\
\hline & & & 30 & 0.9342 & 0.9536 & 98.0 \\
\hline & & & 45 & 0.9586 & 0.9664 & 99.2 \\
\hline \multirow{5}{*}{2500} & \multirow{5}{*}{1000} & \multirow{5}{*}{30} & 5 & 0.8850 & 0.9328 & 94.9 \\
\hline & & & 10 & 0.9062 & 0.9386 & 96.5 \\
\hline & & & 20 & 0.9315 & 0.9528 & 97.8 \\
\hline & & & 30 & 0.9481 & 0.9628 & 98.5 \\
\hline & & & 45 & 0.9663 & 0.9729 & 99.3 \\
\hline
\end{tabular}

Note for Table A1-A3: Among the calculated elastic buckling stresses by FEA, Johnson-Ostenfelt formula used the plastic correction for exceeding 50\% of the yield strength and finally marked as non - dimensional with yield strength.

Table A2. Comparison of elastic-plastic buckling stress for curved plate with simply supported and clamped edges $(\mathrm{a} / \mathrm{b}=3.0)$

\begin{tabular}{|c|c|c|c|c|c|c|}
\hline $\mathrm{a}$ & b & $\mathrm{t}$ & $\theta$ & $\begin{array}{c}\text { Simply Supported } \\
\left(\sigma_{C R_{-} S S}\right)\end{array}$ & $\begin{array}{l}\text { Clamped } \\
\left(\sigma_{C R_{-} C L}\right)\end{array}$ & $\frac{\sigma_{C R_{-} S S}}{\sigma_{C R_{-} C L}} \times 100(\%)$ \\
\hline \multirow{5}{*}{3000} & \multirow{5}{*}{1000} & \multirow{5}{*}{8} & 5 & 0.2510 & 0.3106 & 80.8 \\
\hline & & & 10 & 0.3643 & 0.5601 & 65.0 \\
\hline & & & 20 & 0.6127 & 0.7592 & 80.7 \\
\hline & & & 30 & 0.7607 & 0.8361 & 91.0 \\
\hline & & & 45 & 0.8388 & 0.8890 & 94.3 \\
\hline
\end{tabular}




\begin{tabular}{|c|c|c|c|c|c|c|}
\hline \multirow{5}{*}{3000} & \multirow{5}{*}{1000} & \multirow{5}{*}{10} & 5 & 0.3501 & 0.5109 & 68.5 \\
\hline & & & 10 & 0.4989 & 0.6692 & 74.5 \\
\hline & & & 20 & 0.7018 & 0.8104 & 86.6 \\
\hline & & & 30 & 0.8107 & 0.8695 & 93.2 \\
\hline & & & 45 & 0.8787 & 0.9116 & 96.4 \\
\hline \multirow{5}{*}{3000} & \multirow{5}{*}{1000} & \multirow{5}{*}{15} & 5 & 0.6427 & 0.7533 & 85.3 \\
\hline & & & 10 & 0.7262 & 0.8100 & 89.6 \\
\hline & & & 20 & 0.8209 & 0.8808 & 93.2 \\
\hline & & & 30 & 0.8786 & 0.9157 & 95.9 \\
\hline & & & 45 & 0.9281 & 0.9417 & 98.6 \\
\hline \multirow{5}{*}{3000} & \multirow{5}{*}{1000} & \multirow{5}{*}{20} & 5 & 0.7775 & 0.8530 & 91.2 \\
\hline & & & 10 & 0.8253 & 0.8766 & 94.1 \\
\hline & & & 20 & 0.8792 & 0.9168 & 95.9 \\
\hline & & & 30 & 0.9140 & 0.9390 & 97.3 \\
\hline & & & 45 & 0.9473 & 0.9571 & 99.0 \\
\hline \multirow{5}{*}{3000} & \multirow{5}{*}{1000} & \multirow{5}{*}{25} & 5 & 0.8458 & 0.9024 & 93.7 \\
\hline & & & 10 & 0.8788 & 0.9145 & 96.1 \\
\hline & & & 20 & 0.9122 & 0.9379 & 97.3 \\
\hline & & & 30 & 0.9351 & 0.9530 & 98.1 \\
\hline & & & 45 & 0.9588 & 0.9664 & 99.2 \\
\hline \multirow{5}{*}{3000} & \multirow{5}{*}{1000} & \multirow{5}{*}{30} & 5 & 0.8869 & 0.9307 & 95.3 \\
\hline & & & 10 & 0.9106 & 0.9376 & 97.1 \\
\hline & & & 20 & 0.9328 & 0.9520 & 98.0 \\
\hline & & & 30 & 0.9491 & 0.9627 & 98.6 \\
\hline & & & 45 & 0.9665 & 0.9726 & 99.4 \\
\hline
\end{tabular}

Table A3. Comparison of elastic-plastic buckling stress for curved plate with simply supported and clamped edges $(\mathrm{a} / \mathrm{b}=3.5)$

\begin{tabular}{|c|c|c|c|c|c|c|}
\hline $\mathrm{a}$ & $\mathrm{b}$ & $\mathrm{t}$ & $\theta$ & $\begin{array}{l}\text { Simply Supported } \\
\qquad\left(\sigma_{C R_{-} S S}\right)\end{array}$ & $\begin{array}{l}\text { Clamped } \\
\left(\sigma_{C R_{-} C L}\right)\end{array}$ & $\frac{\sigma_{C R_{-} S S}}{\sigma_{C R_{-} C L}} \times 100(\%)$ \\
\hline \multirow{5}{*}{3500} & \multirow{5}{*}{1000} & \multirow{5}{*}{8} & 5 & 0.2577 & 0.3052 & 84.4 \\
\hline & & & 10 & 0.3718 & 0.5592 & 66.5 \\
\hline & & & 20 & 0.6162 & 0.7581 & 81.3 \\
\hline & & & 30 & 0.7615 & 0.8355 & 91.1 \\
\hline & & & 45 & 0.8386 & 0.8891 & 94.3 \\
\hline \multirow{5}{*}{3500} & \multirow{5}{*}{1000} & \multirow{5}{*}{10} & 5 & 0.3644 & 0.5063 & 72.0 \\
\hline & & & 10 & 0.5104 & 0.6660 & 76.6 \\
\hline & & & 20 & 0.7053 & 0.8102 & 87.1 \\
\hline & & & 30 & 0.8117 & 0.8693 & 93.4 \\
\hline & & & 45 & 0.8790 & 0.9116 & 96.4 \\
\hline \multirow{5}{*}{3500} & \multirow{5}{*}{1000} & \multirow{5}{*}{15} & 5 & 0.6374 & 0.7499 & 85.0 \\
\hline & & & 10 & 0.7332 & 0.8085 & 90.7 \\
\hline & & & 20 & 0.8240 & 0.8808 & 93.5 \\
\hline & & & 30 & 0.8797 & 0.9152 & 96.1 \\
\hline & & & 45 & 0.9281 & 0.9417 & 98.6 \\
\hline \multirow{5}{*}{3500} & \multirow{5}{*}{1000} & \multirow{5}{*}{20} & 5 & 0.7762 & 0.8505 & 91.3 \\
\hline & & & 10 & 0.8287 & 0.8758 & 94.6 \\
\hline & & & 20 & 0.8816 & 0.9160 & 96.2 \\
\hline & & & 30 & 0.9152 & 0.9385 & 97.5 \\
\hline & & & 45 & 0.9475 & 0.9569 & 99.0 \\
\hline
\end{tabular}




\begin{tabular}{|c|c|c|c|c|c|c|}
\hline \multirow{5}{*}{3500} & \multirow{5}{*}{1000} & \multirow{5}{*}{25} & 5 & 0.8458 & 0.9011 & 93.9 \\
\hline & & & 10 & 0.8788 & 0.9139 & 96.2 \\
\hline & & & 20 & 0.9139 & 0.9374 & 97.5 \\
\hline & & & 30 & 0.9361 & 0.9529 & 98.2 \\
\hline & & & 45 & 0.9590 & 0.9662 & 99.3 \\
\hline \multirow{5}{*}{3500} & \multirow{5}{*}{1000} & \multirow{5}{*}{30} & 5 & 0.8869 & 0.9296 & 95.4 \\
\hline & & & 10 & 0.9091 & 0.9367 & 97.1 \\
\hline & & & 20 & 0.9345 & 0.9515 & 98.2 \\
\hline & & & 30 & 0.9499 & 0.9624 & 98.7 \\
\hline & & & 45 & 0.9667 & 0.9724 & 99.4 \\
\hline
\end{tabular}

Table A4. Comparison of ultimate strength for curved plate with simply supported and clamped edges $(\mathrm{a} / \mathrm{b}=2.5)$

\begin{tabular}{|c|c|c|c|c|c|c|}
\hline A & b & $\mathrm{t}$ & $\theta$ & $\begin{array}{c}\text { Simply Supported } \\
\left(\sigma_{U_{-} s S}\right)\end{array}$ & $\begin{array}{l}\text { Clamped } \\
\left(\sigma_{U_{-} C L}\right)\end{array}$ & $\frac{\sigma_{U_{-} S S}}{\sigma_{U_{-} C L}} \times 100(\%)$ \\
\hline \multirow{5}{*}{2500} & \multirow{5}{*}{1000} & \multirow{5}{*}{8} & 5 & 0.4903 & 0.4532 & 108.2 \\
\hline & & & 10 & 0.4982 & 0.4747 & 105.0 \\
\hline & & & 20 & 0.5603 & 0.5526 & 101.4 \\
\hline & & & 30 & 0.6336 & 0.5990 & 105.8 \\
\hline & & & 45 & 0.6319 & 0.6833 & 92.5 \\
\hline \multirow{5}{*}{2500} & \multirow{5}{*}{1000} & \multirow{5}{*}{10} & 5 & 0.5819 & 0.5378 & 108.2 \\
\hline & & & 10 & 0.5960 & 0.5825 & 102.3 \\
\hline & & & 20 & 0.6575 & 0.6988 & 94.1 \\
\hline & & & 30 & 0.7219 & 0.7609 & 94.9 \\
\hline & & & 45 & 0.7575 & 0.8118 & 93.3 \\
\hline \multirow{5}{*}{2500} & \multirow{5}{*}{1000} & \multirow{5}{*}{15} & 5 & 0.6096 & 0.7457 & 81.7 \\
\hline & & & 10 & 0.7798 & 0.7836 & 99.5 \\
\hline & & & 20 & 0.8330 & 0.8450 & 98.6 \\
\hline & & & 30 & 0.8702 & 0.9046 & 96.2 \\
\hline & & & 45 & 0.9123 & 0.9244 & 98.7 \\
\hline \multirow{5}{*}{2500} & \multirow{5}{*}{1000} & \multirow{5}{*}{20} & 5 & 0.8455 & 0.9144 & 92.5 \\
\hline & & & 10 & 0.9110 & 0.9254 & 98.4 \\
\hline & & & 20 & 0.9310 & 0.9478 & 98.2 \\
\hline & & & 30 & 0.9433 & 0.9495 & 99.3 \\
\hline & & & 45 & 0.9524 & 0.9684 & 98.3 \\
\hline \multirow{5}{*}{2500} & \multirow{5}{*}{1000} & \multirow{5}{*}{25} & 5 & 0.9505 & 0.9859 & 96.4 \\
\hline & & & 10 & 0.9716 & 0.9827 & 98.9 \\
\hline & & & 20 & 0.9743 & 0.9820 & 99.2 \\
\hline & & & 30 & 0.9760 & 0.9849 & 99.1 \\
\hline & & & 45 & 0.9768 & 0.9861 & 99.1 \\
\hline \multirow{5}{*}{2500} & \multirow{5}{*}{1000} & \multirow{5}{*}{30} & 5 & 0.9880 & 0.9989 & 98.9 \\
\hline & & & 10 & 0.9919 & 0.9983 & 99.4 \\
\hline & & & 20 & 0.9923 & 0.9968 & 99.5 \\
\hline & & & 30 & 0.9917 & 0.9966 & 99.5 \\
\hline & & & 45 & 0.9903 & 0.9937 & 99.7 \\
\hline
\end{tabular}

Table A5. Comparison of ultimate strength for curved plate with simply supported and clamped edges $(\mathrm{a} / \mathrm{b}=3.0)$ 


\begin{tabular}{|c|c|c|c|c|c|c|}
\hline $\mathrm{a}$ & $\mathrm{b}$ & $\mathrm{t}$ & $\theta$ & $\begin{array}{l}\text { Simply Supported } \\
\left(\sigma_{U_{-} s S}\right)\end{array}$ & $\begin{array}{l}\text { Clamped } \\
\left(\sigma_{U_{-} C L}\right)\end{array}$ & $\frac{\sigma_{U_{-} S S}}{\sigma_{U_{-} C L}} \times 100(\%)$ \\
\hline \multirow{5}{*}{3000} & \multirow{5}{*}{1000} & \multirow{5}{*}{8} & 5 & 0.4555 & 0.4557 & 100.0 \\
\hline & & & 10 & 0.5030 & 0.4823 & 104.3 \\
\hline & & & 20 & 0.5622 & 0.5479 & 102.6 \\
\hline & & & 30 & 0.6345 & 0.5956 & 106.5 \\
\hline & & & 45 & 0.6387 & 0.7080 & 90.2 \\
\hline \multirow{5}{*}{3000} & \multirow{5}{*}{1000} & \multirow{5}{*}{10} & 5 & 0.4565 & 0.5390 & 84.7 \\
\hline & & & 10 & 0.6007 & 0.5691 & 105.6 \\
\hline & & & 20 & 0.6597 & 0.6803 & 97.0 \\
\hline & & & 30 & 0.7230 & 0.7474 & 96.7 \\
\hline & & & 45 & 0.7645 & 0.8065 & 94.8 \\
\hline \multirow{5}{*}{3000} & \multirow{5}{*}{1000} & \multirow{5}{*}{15} & 5 & 0.6995 & 0.7428 & 94.2 \\
\hline & & & 10 & 0.7851 & 0.7904 & 99.3 \\
\hline & & & 20 & 0.8353 & 0.8584 & 97.3 \\
\hline & & & 30 & 0.8711 & 0.8919 & 97.7 \\
\hline & & & 45 & 0.9139 & 0.9197 & 99.4 \\
\hline \multirow{5}{*}{3000} & \multirow{5}{*}{1000} & \multirow{5}{*}{20} & 5 & 0.8937 & 0.9188 & 97.3 \\
\hline & & & 10 & 0.9066 & 0.9264 & 97.9 \\
\hline & & & 20 & 0.9318 & 0.9371 & 99.4 \\
\hline & & & 30 & 0.9437 & 0.9572 & 98.6 \\
\hline & & & 45 & 0.9519 & 0.9655 & 98.6 \\
\hline \multirow{5}{*}{3000} & \multirow{5}{*}{1000} & \multirow{5}{*}{25} & 5 & 0.9661 & 0.9896 & 97.6 \\
\hline & & & 10 & 0.9660 & 0.9842 & 98.2 \\
\hline & & & 20 & 0.9743 & 0.9789 & 99.5 \\
\hline & & & 30 & 0.9760 & 0.9824 & 99.3 \\
\hline & & & 45 & 0.9764 & 0.9819 & 99.4 \\
\hline \multirow{5}{*}{3000} & \multirow{5}{*}{1000} & \multirow{5}{*}{30} & 5 & 0.9901 & 0.9995 & 99.1 \\
\hline & & & 10 & 0.9908 & 0.9988 & 99.2 \\
\hline & & & 20 & 0.9915 & 0.9978 & 99.4 \\
\hline & & & 30 & 0.9914 & 0.9953 & 99.6 \\
\hline & & & 45 & 0.9935 & 0.9960 & 99.7 \\
\hline
\end{tabular}

Table A6. Comparison of ultimate strength for curved plate with simply supported and clamped edges $(\mathrm{a} / \mathrm{b}=3.5)$

\begin{tabular}{|c|c|c|c|c|c|c|}
\hline $\mathrm{a}$ & $\mathrm{b}$ & $\mathrm{t}$ & $\theta$ & $\begin{array}{c}\text { Simply Supported } \\
\left(\sigma_{U_{-} S S}\right)\end{array}$ & $\begin{array}{l}\text { Clamped } \\
\left(\sigma_{U_{-} C L}\right)\end{array}$ & $\frac{\sigma_{U_{-} S S}}{\sigma_{U_{-} C L}} \times 100(\%)$ \\
\hline \multirow{5}{*}{3500} & \multirow{5}{*}{1000} & \multirow{5}{*}{8} & 5 & 0.4071 & 0.4525 & 90.0 \\
\hline & & & 10 & 0.5073 & 0.4740 & 107.0 \\
\hline & & & 20 & 0.5638 & 0.5731 & 98.4 \\
\hline & & & 30 & 0.6355 & 0.6085 & 104.4 \\
\hline & & & 45 & 0.6436 & 0.6992 & 92.0 \\
\hline \multirow{6}{*}{3500} & \multirow{6}{*}{1000} & \multirow{6}{*}{10} & 5 & 0.3969 & 0.5355 & 74.1 \\
\hline & & & 10 & 0.6052 & 0.5726 & 105.7 \\
\hline & & & 20 & 0.6622 & 0.6558 & 101.0 \\
\hline & & & 30 & 0.7239 & 0.7376 & 98.1 \\
\hline & & & 45 & 0.7679 & 0.7823 & 98.2 \\
\hline & & & 5 & 0.6059 & 0.7432 & 81.5 \\
\hline
\end{tabular}




\begin{tabular}{|c|c|c|c|c|c|c|}
\hline \multirow{4}{*}{3500} & \multirow{4}{*}{1000} & \multirow{4}{*}{15} & 10 & 0.7736 & 0.7878 & 98.2 \\
\hline & & & 20 & 0.8372 & 0.8455 & 99.0 \\
\hline & & & 30 & 0.8718 & 0.8771 & 99.4 \\
\hline & & & 45 & 0.9164 & 0.9140 & 100.3 \\
\hline \multirow{5}{*}{3500} & \multirow{5}{*}{1000} & \multirow{5}{*}{20} & 5 & 0.8339 & 0.9166 & 91.0 \\
\hline & & & 10 & 0.9088 & 0.9197 & 98.8 \\
\hline & & & 20 & 0.9324 & 0.9426 & 98.9 \\
\hline & & & 30 & 0.9431 & 0.9539 & 98.9 \\
\hline & & & 45 & 0.9525 & 0.9635 & 98.9 \\
\hline \multirow{5}{*}{3500} & \multirow{5}{*}{1000} & \multirow{5}{*}{25} & 5 & 0.9411 & 0.9896 & 95.1 \\
\hline & & & 10 & 0.9657 & 0.9822 & 98.3 \\
\hline & & & 20 & 0.9737 & 0.9798 & 99.4 \\
\hline & & & 30 & 0.9758 & 0.9790 & 99.7 \\
\hline & & & 45 & 0.9767 & 0.9798 & 99.7 \\
\hline \multirow{5}{*}{3500} & \multirow{5}{*}{1000} & \multirow{5}{*}{30} & 5 & 0.9860 & 0.9995 & 98.6 \\
\hline & & & 10 & 0.9887 & 0.9992 & 98.9 \\
\hline & & & 20 & 0.9912 & 0.9965 & 99.5 \\
\hline & & & 30 & 0.9912 & 0.9954 & 99.6 \\
\hline & & & 45 & 0.9900 & 0.9959 & 99.4 \\
\hline
\end{tabular}

